\title{
EL PROYECTO VITAL DE AVERROES: EXPLICAR E INTERPRETAR A ARISTÓTELES
}

\author{
JoseP PUIG MonTADA \\ Universidad Complutense
}

Averroes (1123-1198) nunca pretendió ser un pensador original, a diferencia de Avicena (m. 1037) y aunque nosotros sí reconozcamos su originalidad. Consideró que en Aristóteles se encontraba la sabiduría máxima y que el filósofo alcanzaba ésta cuando comprendía a Aristóteles. Para entenderlo, se propuso primero exponer el contenido de sus obras y luego comentar éstas detenidamente.

\section{Explicar a Aristóteles}

Los folios $82 \mathrm{v}^{\circ}$ y $83 \mathrm{r}^{\circ}$ del manuscrito de El Escorial n. ${ }^{\circ} 884$, en el catálogo de Derenbourg (879 en el de Casiri), contienen una lista de las obras de Averroes que M. Cruz Hernández ha estudiado ${ }^{1}$, y que G.C. Anawati ya recogía en su bibliografía ${ }^{2}$. Suponemos que está hecha por uno de sus nietos, Abū 1- ${ }^{\mathrm{c}} \mathrm{Abbās}$ Yahyà, pues éste figura como autor de las listas de obras de Avicena y Alfarabi que la preceden. Se trata, pues, de un documento antiguo y fidedigno, aunque el copista cometió bastantes errores.

Los autores de fihris o repertorios bio-bibliográficos corroboran los datos de esta lista. La que nos da Ibn Abī Ușaybica (m. 668/ $1270)^{3}$ no es tan completa y además atribuye a Averroes obras de su abuelo, como el Libro del refinado (tahsili) o El libro de las premisas en derecho. Las obras que Ibn Abī Ușaybica enumera se marcan en la lista que sigue con (U). En cambio, la de otro historiador, Muhammad al-A শ̣cī al-Anșārī al-Marrākušĩ (m. 1302) coincide casi siempre con

${ }^{1}$ Abū l-Walìd Muhammad Ibn Rušd (Averroes), 2. a ed. Córdoba, 1997, 359-369.

${ }^{2}$ Bibliographie d'Averroès, Argel, 1978, 36-40.

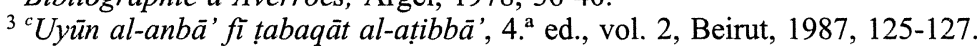

Al-Qanțara XXIII, 1 (2002) 11-52 
la lista de El Escorial y, en algunos casos, es más exacta 4 ; las obras que enumera se marcan en nuestra lista con (M). Los títulos de las obras, en español, son los siguientes:

1. Lo necesario en lógica (ḍarūrī) (U M).

2. Las sumas (ŷāāmic en filosofia $(\mathrm{U} \mathrm{M})$.

3. Compendio (mujtasar) del Almagesto (M).

4. Sumas (ŷawāmic) de la República de Platón (M).

5. Lo que es necesario del libro de Euclides sobre el Almagesto (M).

6. Paráfrasis (taljīs) del De physico auditu (U M).

7. Paráfrasis del De caelo et mundo (U M).

8. Paráfrasis del De generatione et corruptione (M).

9. Paráfrasis de Meteorologica (M).

10. Paráfrasis del De anima (U M).

11. Paráfrasis de nueve tratados (maqāla) del libro de los Animales, que van del undécimo hasta el final de la colección (U M).

12. Paráfrasis del De sensu et sensato (M).

13. Paráfrasis del libro de Nicolás (U M) ${ }^{5}$.

14. Paráfrasis de la Metafísica (U M).

15. Paráfrasis del libro de los caracteres (U M). La ética es la ciencia de los caracteres, de modo que Averroes resume la Ética a $\mathrm{Ni}$ comaco.

16. Comentario (šarh) al De caelo et mundo (M).

17. Comentario al De physico auditu (M).

18. Comentario al De anima (M).

19. Comentario al libro de la demostración (Analíticos Posteriores) (M).

20. Paráfrasis del libro de Aristóteles sobre lógica (U). Debe referirse a todo el Organon.

21. Comentario a la Metafísica (M).

22. Refutación del libro de la Ruina, o Tahāfut al-falāsifa (U M) de Algacel.

23. Los universales en medicina (U M).

24. Paráfrasis de los Elementos de Galeno (U).

${ }^{4}$ Abū c Abd Allāh Muhammad al-Awsī al-Anșārī al-Marrākušī (m. 1303), Al-Dayl wa-l-takmila li-kitābay al-Mawsūl wa-Sila, ed. I. 'Abbās, vol. 6, Beirut, 1973, 22-24.

${ }^{5}$ Nicolás de Damasco (ca. 40 a.C. -20 p.C.) es autor de un comentario a la Metafisi$c a$, al que Averroes se refiere en su comentario mayor a la misma. Cf. Pawlys Realencyclopädie der classischen Altertumswissenschaft, vol. XVII/1 s.v. 
25. Libro sobre el Temperamento del mismo (U).

26. Paráfrasis de las Potencias naturales (U).

27. Paráfrasis de las Enfermedades y síntomas (U M).

28. Paráfrasis de los Órganos dolorosos (M).

29. Paráfrasis del libro de las Fiebres del mismo (U M).

$183 \mathrm{r} / 30$. Paráfrasis de los cinco primeros capitulos del libro de los Medicamentos simples del mismo (U M).

31. Paráfrasis del Comentario de Abū Nașr (Alfarabi al) Tratado primero del Silogismo del Sabio (Aristóteles) (U M).

32. Manual del que se esfuerza por una interpretación y la finalidad del que sigue el justo término medio. El copista ha cambiado el orden y una palabra, y literalmente dice: Libro de la finalidad del que sigue el justo término medio y del objetivo del que se esfuerza por una interpretación, en derecho (U M).

33. Cuestiones (masā'il) țubbülìya (U), sin duda un error, en vez de țibbìya, 'médicas' que es lo que lee al-Awsī al-Marrākušī (M). De ser țubbülīya correcto, serían unas extrañas 'cuestiones fiscales' (U).

34. Lo necesario en gramática (M).

35. Libro de los métodos en los fundamentos de la religión (U M).

36. Comentario a la Epístola de la conjunción del entendimiento humano, de Avempace (U M).

37. Tratado definitivo (Fașl al-maqāl), en fundamentos (de la religión) (U M). El título completo, y así lo da al-Awsī al-Marrākušī, es Tratado definitivo probando la coincidencia entre la ley musulmana y la sabiduría.

38. Abreviación de los dos Mustașfà. Sin embargo, con ayuda de al-Awsī al-Marrākušĩ corregimos 'del Mustașfà', que es una obra de Algacel, acerca de los fundamentos de la religión (M).

39. Comentario del tratado de Alejandro Sobre el entendimiento (U M).

40. Cuestiones sobre el libro del alma (M).

41. Cuestiones demostrativas (U) entiendo: lógicas.

42. Palabras sobre lo dicho al principio del libro de Abü Nașr (Alfarabi) (M).

43. Tratado sobre la Triaca (U M).

44. Palabras acerca de lo que dice Abū Nașr acerca de la Isagoge «el género y la diferencia especifica participan» (M).

45. Paráfrasis de la Isagoge según Porfirio. 
46. Anotación incompleta del principio de la Demostración de $A b \bar{u} \operatorname{Nașr}(\mathrm{M})$.

47. Tratado sobre el cuerpo celeste (M).

48. Tratado sobre lo predicable del todo (M).

49. Tratado sobre la premisa absoluta (M).

50. Otro tratado sobre el cuerpo celeste (M).

51. Otro tratado también sobre el mismo (M).

52. Cuestión sobre la ciencia del alma, la pone y la contesta.

53. Tratado sobre la ciencia del alma (M).

54. Otro tratado también sobre la ciencia del alma (M).

55. Comentario al credo del imām el Guía, o sea Ibn Tūmart (M) ${ }^{6}$.

56. Comentario a la Urŷūza de Avicena sobre la medicina (UM).

57. Tratado sobre el temperamento equilibrado (M).

58. Palabras sobre una cuestión de Las enfermedades y los síntomas (M).

59. Tratado sobre la concordancia entre la creencia de los peripatéticos y los mutakallimies, entre los sabios musulmanes, en cómo es la existencia del mundo en cuanto a la eternidad y la creación temporal (U M).

60. Palabras suyas sobre el verbo y el nombre derivado (M).

61. Tratado sobre la forma de la inferencia de las conclusiones de los silogismos mixtos (M).

62. Tratado sobre la sustancia del universo (M).

63. Anotación (ta'līq) sobre la Demostración del sabio (M).

64. Palabras sobre una cuestión del De caelo et mundo (M).

65. Tratado sobre el semen y la semilla (M).

66. Anotación al tratado séptimo y octavo del De physico auditu (M).

67. Palabras suyas sobre Los animales (M).

68. Palabras suyas sobre el primer motor (M).

69. Palabras suyas sobre el movimiento del cuerpo celeste (M).

70. Otras palabras también sobre ello (M).

71. Tratado sobre los silogismos condicionales.

72. Cuestión de si Dios conoce los particulares (M).

${ }^{6}$ M. al-Awsī al-Anșārī al-Marrākušī, en la edición del equipo de I. 'Abbās, dice 'credo de Humrān' ('aqïla humrānìya). El manuscrito ha sido descubierto recientemente por Mohamed Bencherifa, de la Academia Real de Marruecos, quien lo está editando. 
73. Palabras sobre la visión del cuerpo fijo en círculos. Aquí la edición dirigida por I. 'Abbās de al-Dayl de M. al-Awsī al-Marrākušī diverge de El Escorial: «Tratado sobre el acceso permanente de fiebre en paroxismos» (M).

74. Tratado sobre la existencia eterna y la existencia temporal. (M).

75. Tratado sobre cómo entra (lo eterno) en lo natural, su estudio $y$ excelencia de la ciencia del imām el Guía ${ }^{7}$ (M).

76. Muchas cuestiones y notas (taqāyīd) sobre artes varias y sintomas varios.

Ibn Abī Ușaybi ${ }^{c} a$ añade otros títulos ${ }^{8}$, que Ŷamāl al-Dīn al- ${ }^{\mathrm{c}}$ Alawī tuvo muy en cuenta y que le llevaron a establecer una lista de 108 obras de Averroes ${ }^{9}$. Para nuestro análisis vamos a limitarnos a este documento de indiscutible autenticidad como es la lista de El Escorial.

En esta lista, y según los títulos, vemos que los géneros que aparecen con mayor frecuencia son taljīṣ 'exposición, paráfrasis' y šarḥ 'comentario literal'. Otros géneros son masā'il 'cuestiones', mujtasar 'compendio', maqāla 'tratado', ta'līq, 'anotación', y uno muy impreciso de kalām 'palabras'. Ŷawāmic aparece dos veces: como sumas de filosofía (de la Física a la Metafisica) y de la República. Elamrani-Ŷamāl se preguntaba con razón si ante tal variedad de géneros se puede mantener la imagen del Averroes «comentador» ${ }^{10}$.

Hay dos términos, sin embargo, que encajan con esta actividad relacionada estrechamente con el texto aristotélico: taljī̦ 'exposición' y šarh 'comentario'. Es evidente que taljị̦ y šarḥ no sólo son más frecuentes que otros, sino también aparecen como complementarios; por ejemplo, para la Metafisica hay tanto un comentario como una paráfrasis.

\footnotetext{
${ }^{7}$ Completado con ayuda de al-Anșārī al-Marrākušī, al-Dayl wa-l-takmila, p. 23: 7-8.

${ }^{8} \mathrm{Ibn}$ Abī Usaybic ${ }^{\mathrm{c}}$ a añade: Comentario al libro del silogismo (Analíticos Primeros), y dos obras del abuelo de Averroes: Kitāb al-tahșïl, y las Muqaddamät fi l-fiqh.

Además, hay que observar que al-Awsī al-Anșārī al-Marrākušĩ incluye dos tratados que probablemente no son de Averroes:

Cómo el sordo es llamado a entrar en el islam.

[Comentario] Sobre los nueve tratados sobre el arte de la convalescencia.

${ }^{9}$ Al-matn al-rušdi, "El corpus averroico", Casablanca, 1986, 14-45.

${ }_{10}$ "Averroès, le commentateur d'Aristote?», M. Sinnaceur (ed.), Penser avec Aristote, París-Tolouse, 634-651.
} 
Taljịs es además un término que se explica en la biografía de Averroes. El historiador de los almohades, 'Abd al-Wāhid al-Marrākušī, pone en boca de Abū Bakr Ibn Țufayl estas palabras dirigidas a su amigo y discípulo Averroes:

Hoy he oído al Príncipe de los creyentes [Abū $\mathrm{Ya}^{\mathrm{c}} \mathrm{qūb}$ ] quejarse de las dificultades de la expresión de Aristóteles o de sus traductores y señalar la oscuridad de sus intenciones. Decía: «Si hubiera alguien que expusiera y sintetizara - hiciera taljis - estos libros, y que una vez hubiera entendido bien sus intenciones, las hiciera accesibles, la gente alcanzaría su contenido. Si tienes capacidad suficiente para ello, hazlo».

Te pido [yo, Ibn Tufayl] que lo hagas porque conozco tu buena inteligencia, tu talento lúcido, tu fuerte inclinación para la ciencia. Lo que a mí me impide hacerlo, como sabes, es mi avanzada edad, mi empleo al servicio del califa y que estoy ocupado en cosas que para mí son más importantes ${ }^{11}$.

Averroes, a su vez, transmite la información a un amigo, Abū Bakr [Ibn] Bundūd Ibn Yahyyà y le confiesa: «Esto es lo que me impulsó a hacer las paráfrasis que he hecho de las obras de Aristóteles». El amigo ha visto personalmente el Libro de las sumas, arriba indicado, que tiene «unas ciento cincuenta hojas» y sabe que en él Averroes resume la Física, el De caelo, De generatione et corruptione, Meteorologica y De sensu et sensato de Aristóteles. Bundūd añade que luego Averroes hizo paráfrasis de los mismos, lajjașa, y comentarios a sus objetivos, šaraḥa ${ }^{12}$. Bundūd no era un filósofo, y entre las paráfrasis cuenta las sumas, pero la idea fundamental que como lego en filosofía recoge y que coincide con lo que Averroes nos ha dejado, es la de que éste efectuaba dos tipos de trabajo: explicaba las obras de Aristóteles y las comentaba detalladamente, es decir, las interpretaba.

La palabra taljīs será traducida al hebreo por be 'ür ${ }^{13}$, y al latín tractatus, más frecuentemente por commentum ${ }^{14}$ en aquellas traducciones

${ }^{11}$ Al-Mu $u^{c} \hat{y} i b$ fi taljịs ajbār al-Magrib (escrito 1224), ed. R. Dozy, Leiden, 1881, p. 175: 6-13; ed. M. Z. M. 'Azab, Cairo, 1994, p. 203: 16-204: 1. Trad. española de A. Huici Miranda en Colección de crónicas árabes de la reconquista, vol. 4, Tetuán, 1955, 195-196

${ }^{12} \mathrm{Al}-\mathrm{Mu}$ ' $\hat{y} i b$, ed. Dozy, p. 175: 19-20; ed. 'Azab, p. 204: 6. Añade que estos comentarios están en un libro en cuatro tomos.

${ }^{13}$ Steinschneider, M. Die hebraeischen Übersetzungen des Mittelalters und die Juden als Dolmetscher, Berlín, 1893. R. Graz: Akademische Druck- u. Verlagsanstalt, 1956, 49-178.

${ }_{14}$ Los traductores del árabe al latín son tres fundamentalmente: Hermann el Alemán (m. 1272), Miguel el Escocés (m. 1236) y Guillermo de Luna (s. XIII): Steinschneider, 
directas del árabe, efectuadas a principios del siglo XIII. En hebreo se va a precisar más, porque los estudiosos conocen distintos escritos de Averroes sobre un mismo texto aristotélico, y así la paráfrasis, la exposición es be'ür emtsāi, 'exposición media'. Por esto, cuando en pleno renacimiento se traduzca del hebreo al latín, leeremos expositio media, aunque otras veces encontremos paraphrasis. Paráfrasis puede tener un sentido peyorativo, pero si prescindimos de él, describe bien este tipo de trabajo: exponer, explicar, el contenido de una obra con palabras más comprensibles que las del original.

El comentario šarh se traduce al hebreo como pirüšs, y al latín, también como commentum. Cuando en el Renacimiento se perciba la posible confusión, se completa el título en commentarium magnum. Junto a šarh aparece tafsìr, un término de connotaciones religiosas: los comentarios al Corán son tafsīr. Sin embargo, el antecedente preciso está en los comentadores helenísticos, que Averroes conocía bien: así, para él los comentarios de Alejandro suelen ser šarh, y en cambio los de Temistio suelen ser taljịs. Esta es exactamente la distinción que hacía Simplicio, cuando redactaba su comentario al texto aristotélico, pero 'consultando además la exégesis de Alejandro y la paráfrasis de Temis-

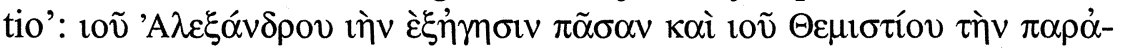

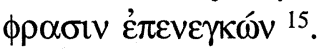

El Renacimiento es por tanto la época en la que se introduce la distinción entre tres comentarios, porque entonces se traducen del hebreo todos sus escritos, incluyendo los mujtașar o los que forman parte de las $\hat{y} a w \bar{a} m i^{c}$. La traducción hebrea de mujtașar es qitsūr y así las palabras de Averroes al comienzo de su «comentario menor» a la $\mathrm{Fi}^{\prime}$ sica aludiendo a al-mujtasar al-sagīr ${ }^{16}$, se convierten en ha-qitsür ha-qațon en la traducción de Moshe ben Ṭibbon ${ }^{17}$. De manera pareci-

M., Die europäischen Übersetzungen aus dem Arabischen bis Mitte des 17. Jahrhunderts, en Sitzugsberichte der philosophisch-historischen Klasse der Kaiserlichen Akademie der Wissenschaften, vol. 149, Viena, 1904. Repr. Graz, 1956, 32-33, 55-58 y 80-81, respectivamente. Lacombe, G. et. al. Aristoteles Latinus. Pars prior, Roma, 1939, 100-111. Una exhaustiva bibliografia la proporciona Hans Daiber: «Lateinische Übersetzungen arabischer Texte zur Philosophie und ihre Bedeutung für die Scholastik des Mittelalters», en J. Hamesse et M. Fattori (eds.) Rencontres de cultures dans la philosophie médiévale, Louvain-la-Neuve/ Cassino, 1990, 203-250.

${ }^{15}$ Simplicii in Aristotelis Physicorum libri quattuor posteriores commentaria. VIII, contra Proclum, ed. H. Diels, Berlín, 1895, p. 1130: 3-4. CiAG X.

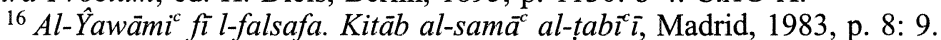

${ }^{17}$ Qitsūr Ibn Rušd ${ }^{c} a l$ šema ' teb 'î, Riva di Trento, 1559, fol. 2 ro, líneas 19-20. 
da, en su «comentario medio» a los Meteorológicos se refiere a sus

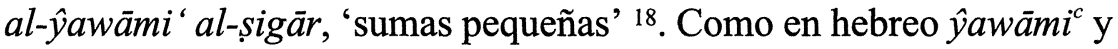
mujtasar recibieron el nombre común de qitsūr, en el latín renacentista, que es versión del hebreo, son epitome, compendium, summa, indistintamente.

En resumen, Averroes define su trabajo con el corpus aristotélico como un trabajo doble, uno de análisis expositivo y otro de comentario. No excluye otras formas, como son los compendios, las cuestiones o kaläm, unas «palabras», pero taljīs y šarh son las fundamentales, y son las formas a cuya composición el sultán $\mathrm{Abū} \mathrm{Ya}{ }^{\mathrm{c}} q u \bar{b}$ le impulsó.

A continuación vamos a considerar los aspectos más señalados de ambos géneros para luego llegar a una conclusión. No se trata aquí de dar una información bibliográfica, hecha exhaustivamente por G. Endress ${ }^{19}$, aunque sean necesarias referencias bibliográficas para este recorrido:

El Órgano aristotélico comprende para Averroes —que sigue la tradición árabe - también la Retórica y la Poética. De las ediciones del taljị̦ hay que destacar la de C.E. Butterworth, Mahmūd Qāsim (m. 1973) y A. ${ }^{\mathrm{C}} \mathrm{A}$. Harīdī, por su amplia base manuscrita ${ }^{20}$, pero la colección no es todavía completa. Los seis comentarios estrictamente lógicos han sido publicados por G. Jéhamy ${ }^{21}$ y para los Recursos de los sofistas hay que recurrir a su edición. Para la paráfrasis de los Tópicos se puede utilizar la de M.S. Sālim ${ }^{22}$, y asimismo para la de la Retórica $^{23}$. El primero de estos taläjịs es el de la Isagoge dé Porfirio, 144: 7.

${ }^{18}$ Taljīṣ al-ātẫr al-'ulwīya. Ed. Ŷamāl ad-Dīn al-'Alawī, Beirut, 1994, p. 116: 17; p.

${ }_{19}$ "Averrois Opera. A Bibliography of Editions and Contributions to the Text», en G. Endress y J.A. Aertsen (eds.) Averroes and the Aristotelian Tradition, Leiden, 1999, 339-384. Otro trabajo a considerar es el de Philipp W. Rosemann, «Averroes: A Catalogue of Editions and Scholarly Writings from 1821 Onwards», Bulletin de Philosophie Médiévale 30 (1988), 153-221.

${ }^{20}$ Cairo: American Research Center, entre 1979 (Taljīs kitāb al-ŷadal), 1980 (Taljīs kitāb al-maqūlāt), 1981 (Taljịs kitäb al-'ibära), 1982 (Taljīs kitāb al-burhãn), 1983 (Taljīs kitāb al-qiyās) y 1987 (Taljī̦ kitāb al-ši 'r).

${ }_{21}^{21}$ Taljị̦ Manțiq Arisțū, 3 vols. Beirut, 1982. Categorías, Interpretación, Analíticos I y II, Tópicos y Recursos de los sofistas. A propósito de la triple publicación del taljịs de De interpretatione, E. Meyer publicó una interesante reseña: «Der mittlere Kommentar des Averroes zur aristotelischen Hermeneutik», Zeitschrift für Geschichte der Arabisch-Islamischen Wissenschaften 1 (1984), 265-287.

${ }^{22}$ Taljī̦ kitāb Aristūtậlīs fí l-ŷadal, Cairo, 1980.

${ }^{23}$ Taljị̦ al-jițâba, Cairo, 1967. 
seguido por el de las Categorías, el cual había sido editado por M. Bouyges en $19322^{24}$.

Bouyges disponía de menos manuscritos que estos editores, pero en cambio consultaba la traducción hebrea ${ }^{25}$ y las dos latinas ${ }^{26}$; al pie de página reprodujo además la versión árabe de las Categorías. Averroes entiende que el principio de la paráfrasis de las Categorías - no de la Isagoge- es a la vez el principio de su exposición de todo el Organon y convencido de su unidad, dice:

El propósito de este escrito es exponer (taljịs) los significados que contienen los libros de Aristóteles referentes al arte de la lógica, y refinarlos $(t a h s i \grave{l} l)$ en la medida de nuestra capacidad, siguiendo nuestra costumbre con todos sus libros ${ }^{27}$.

Averroes juega en la introducción con los sonidos taljịs y tahșìl, un recurso frecuente en la estilística árabe, el taŷannus. Alude a «su costumbre» porque antes de parafrasear las Categorías parece que ya lo había hecho con otros libros, aunque Averroes puede referirse también a otros resúmenes, como las ŷawāmi $i^{c}$. Si consideramos que al final de la «segunda parte» de la paráfrasis de los Tópicos consta esta fecha: 19 de raŷab 563 (29 abril 1168) ${ }^{28}$, que al final del taljịs de la Retórica está la fecha de 5 de muharram $571{ }^{29}$ o sea, 26 julio 1175 , y que entre ambas fechas podemos situar otras paráfrasis no lógicas, por ejemplo de la Física, es fácil pensar que Averroes no había empezado sus talajjịs precisamente por las Categorías.

El método expositivo de Averroes divide las Categorías en tres partes, $\hat{y} u z$ ', la primera, con cinco capítulos, fașl, la segunda, con seis secciones, qism, que a su vez se subdividen en varios capítulos, fașl, y

\footnotetext{
${ }^{24}$ Talkhiç kitab al-maqoulat, reed. Beirut, 1983. Bibliotheca Arabica Scholasticorum.

${ }^{25}$ Jacob Anatoli, yerno de Shemu'el ben Tibbon, tradujo en Nápoles (1232) las paráfrasis de estos cinco libros: Isagoge, Categoriae, De interpretatione, An. Priora, An. Posteriora. Ver Steinschneider, M. Die hebraeischen Übersetzungen, 57-62.

${ }^{26}$ El primer traductor es desconocido, el segundo es Jacob Mantino (m. 1549), y traducía del hebreo. Su versión aparece en la edición de los Iuncta: Aristotelis omnia quae extant opera... Averrois Cordvbensis in ea opera omnes... commentarii, Venecia, 1562, vol. 1, 1. parte: Aristotelis Stagiritae... Praedicamenta, cum Averrois Cordubensis expositione, fols. $22 \mathrm{v}^{\circ}-61 \mathrm{v}^{\circ}$.

${ }^{27}$ Talkhiç kitab al-maqoulat, ed. Bouyges, p. 3: 2-4.

${ }^{28}$ Solamente transmitido por el manuscrito de Florencia. Taljīs... al-ŷadal, ed. Sālim, p. 381: 8; ed. Jéhamy, p. 624: 12-13. E. Meyer ha llamado la atención sobre estas «interpolaciones» del manuscrito florentino en «Der mittlere Kommentar», p. 267.

${ }^{29}$ Taljị̦ al-jiṭäba, ed. Sālim, p. 690: 5-6.
} 
la tercera, dividida en cinco secciones, qism, subdividida en varios capítulos, fașl. Averroes no tiene reparos en repetir a menudo frases de Aristóteles, aunque la arquitectura del discurso es distinta. Esta arquitectura es la bien conocida divisio textus de los autores medievales latinos, y tiene sus raíces en los comentarios del mundo helenístico.

En cambio, en el tratado siguiente, De interpretatione, opta por una división en cinco capítulos, fașl, conocida ya de Alfarabi ${ }^{30}$, y éstos a veces se subdividen en 'exposiciones' qawl. Averroes se esfuerza en adaptar un análisis basado en el griego a las peculiaridades del árabe. Por ejemplo, Aristóteles en De interpretatione 16 b 1-5, dice que «de Filón» (genitivo), «para Filón» (dativo) no son nombres sino casos de un nombre. Con ellos no se puede formar ninguna frase válida, pues si los unimos a formas del verbo «ser» no decimos nada verdadero ni falso. Averroes explica el sentido del pasaje de este modo:

\begin{abstract}
Asimismo el nombre, si está en acusativo o genitivo, o con una alteración parecida, no se dice que es nombre en absoluto, sino nombre declinado. Habrá pues nombres declinados e indeclinados. La definición con que se define el nombre, los abarca a todos. La diferencia entre declinable e indeclinable - este es el nominativo en árabe - consiste en que si a los nombres declinados - éstos también se llaman oblicuos - se les añade «fue» o «será» o «es» (هـ الآن), y se dice «Zaid fue» en acusativo, o «Zaid será» en genitivo, no resulta algo verdadero o falso. ${ }^{31}$
\end{abstract}

En cambio, estos verbos añadidos al nominativo forman una oración, que es verdadera o falsa. Averroes no ha hecho una lectura literal. La gramática nacional árabe no distingue entre conjugación y declinación, las palabras admiten flexión o no, y el nominativo pertenece a la categoría no flexionada.

R. Hissette ha editado la traducción latina del árabe hecha por Guillermo de Luna de este taljīs ${ }^{32}$, traducción que haría para Federico II en Sicilia (siglo XIII). Allí fașl se traduce por differentia y qawl por dictio, y vemos cómo el traductor a su vez tiene que explicar al lector latino las características de la gramática árabe. Si nos fijamos en el mismo pasaje, G. de Luna nos aclara que «el no declinado es el

${ }^{30}$ Zimmermann, F.W. (ed.), Al-Farabi's Commentary and Short Treatise on Aristotle's De interpretatione, $2^{\mathrm{a}}$ ed., Oxford UP, 1991.

${ }^{31}$ Taljịs kitãb al-ibāra, ed. Butterworth-Harīdī, p. 60: 12- 61: 5.

${ }^{32}$ Commentvm medivm svper libro Peri hermeneias Aristotelis, ed. de R. Hissette, Leuven, 1996. Averrois Opera. Series B. Averroes Latinus XII. 
que lleva el caso /-u/ en árabe» ${ }^{33}$. Existe una traducción hebrea por Jacob Anatoli (marzo-abril 1232), que sigue inédita, y Mantino (m. 1529) la utilizó para su traducción latina, la que aparece en la edición de los Iuncta ${ }^{34}$. Mantino consideró innecesaria la explicación sobre la vocal del caso y en lugar de declinatum escribió obliquum ${ }^{35}$.

En cuanto a los Analíticos Primeros, la división es en dos maqāla, 'tratados', correspondiendo a los dos libros del original en Aristóteles. Luego distribuye el primer tratado en una primera parte, sin denominación, y tres capítulos, y el segundo, en once capítulos; como se ve, no se ajusta a la división habitual del texto aristotélico. La edición de Harīdī y Butterworth ${ }^{36}$ destaca que uno de los manuscritos utilizados, Leiden Biblioteca Universitaria n..$^{\circ} 2073$, de letra magrebí y que bien pudiera ser de procedencia andalusí, añade un texto que viene a ser la respuesta de Averroes a cuestiones sobre los silogismos «mixtos». La traducción latina que aparece en la edición de los Iuncta es atribuida a Ioanne Francisco Burana Veronensi interprete ${ }^{37}$, y en cualquier caso es una traducción a partir de la versión hebrea de $\mathrm{J}$. Anatoli.

En un estudio reciente de esta paráfrasis ${ }^{38}$, S. Harvey llama la atención sobre un aspecto que afecta a la materia de los silogismos y que uno no se espera de un tratado como los Analíticos Primeros: su repercusión en lo teológico. Harvey recoge tres casos en los que Averroes utiliza ejemplos teológicos, donde la silogística sirve para demostrar que el mundo es creado ${ }^{39}$. Esto significa que Averroes no tan sólo se limita a exponer a Aristóteles, su objetivo principal, sino también se esfuerza en integrar cada obra en su conjunto. 79-80.

${ }^{33}$ Et non declinatum (et illud est in caso ' $u$ ' in lingua arabica), ed. Hissette, p. 7: 1.

${ }^{34}$ Como en nota 22, vol. 1, 1. ${ }^{\mathrm{a}}$ parte, fol. $68 \mathrm{r} \mathrm{r}^{\mathrm{o}}$ : Aristotelis De interpretatione liber primvs, Severino Boetho interprete, cum Averrois Cordubensis expositione. El comentario medio de Averroes está intercalado, fols. 68-106. Para un análisis de todas las ediciones renacentistas, ver Hissette, op.cit., en nota 32 pp. 19*-24*.

${ }^{35}$ Aristotelis De interpretatione, vol. 1, pars I, fol. 70 A.

${ }^{36}$ Taljị̦ kitāb al-qiyās, 161-171.

${ }^{37}$ Como en nota 26, vol. 1, 2. ${ }^{a}$ parte: Aristotelis priorvm resolvtoriorvm liber primvs, cum Auerrois Cordubensis media expositione, fols. $1-168 \mathrm{v}^{\circ}$.

38 "Averroes' use of Examples in his Middle Commentary on the Prior Analytics and Some Remarks on his Role as Commentator», Arabic Science and Philosophy 7 (1997), 91-114.

39 «Averroes' use of Examples», 100-103. 
Para el taljịs de los Segundos Analíticos podemos utilizar también la edición de 'Abd al-Rahmān Badawī ${ }^{40}$. Averroes se refiere a ellos como Kitāb al-burhān, 'libro del silogismo apodíctico' o de la 'demostración', y su taljịs respeta la división en dos libros, uno acerca del silogismo apodíctico, otro acerca de la definición. La traducción latina publicada por los Iuncta es atribuida también a Ioan. Francisco Burana Veronensi ${ }^{41}$.

En cuanto a los Tópicos, el original griego está dividido en ocho libros, y Averroes se ajusta a la división, aunque él mismo divida el contenido de la obra en tres partes: la primera coincide con el libro I de Aristóteles, la segunda, con los libros II a VII, y la tercera con el libro VIII ${ }^{42}$. En la parte 2. ${ }^{a}$ quiere definir «los lugares comunes», y para ello considera las opiniones de Alejandro de Afrodisia y Teofrasto, de Temistio y de Alfarabi, sobre lo dicho por Aristóteles, para dar finalmente su parecer. Este procedimiento lo denomina taljišs: 'Esto es una exposición (breve) de lo que son los lugares comunes' ${ }^{43}$.

Tópicos y Recursos de los sofistas fueron traducidos al hebreo por Qalonimoṣ ben Qalonimoș, de Arles, en 1313; más adelante volveremos a encontrar a Qalonimos, muerto en Avignon en 1314, como traductor de Averroes al hebreo ${ }^{44}$. Abraham ben Meir de Balmes y Jacob Mantino tradujeron su versión hebrea de los Tópicos al latín, y las dos traducciones fueron impresas en columnas paralelas, en el Renacimiento ${ }^{45}$. Por el contrario, solamente Abraham de Balmes tradujo la paráfrasis de los Recursos de los sofistas ${ }^{46}$.

En la paráfrasis de los Recursos de los sofistas, Averroes nos sorprende por el cambio en el método. Su comentario es aquí básicamente una paráfrasis del texto aristotélico, cuyos párrafos introduce abiertamente con un qāla, 'dice'. Al final nos confiesa sus dificultades:

\footnotetext{
${ }^{40}$ Šarh al-burhān li-Arisțū wa-taljīṣ al-burhān, Kuwait, 1984, 43-153.

${ }^{41}$ Aristotelis omnia quae extant opera... Averrois Cordvbensis in ea opera omnes.. commentarii, Venecia, 1562, Primi Voluminis Pars II. Averrois expositionis mediae in librum Demonstrationis Aristotelis tractatvs primvs, fol. 1 (texto, fols. 1-35 vo).

${ }^{42}$ Taljịs kitāb Aristūtụtälis fì l-vadal. ed. Sālim. 6-7.

${ }^{43}$ Id., ed. Sālim, p. 78: 7 هزا تلخيص ما هي المراضع :

${ }^{44}$ Steinschneider, M. Die hebraeischen Übersetzungen, p. 62.

${ }^{45}$ Primi Voluminis Pars III. Aristotelis Stagiritae Topicorum atque Elenchorum libri, cvm Averrois Cordvudensis in eos media expositione. La paráfrasis de Topica está intercalada en la obra, fols. 3-138 verso.

${ }^{46}$ Igual que en nota anterior: Primi Voluminis Pars III; la paráfrasis de los Soph. Elenc. está intercalada en fols. 139-176 verso.
} 
Este es el final con el que este hombre termina este libro suyo. Hemos extraído lo que conduce a nuestra comprensión en la medida en que nos es posible en este momento. Volveremos a examinarlo si Dios nos da vida suficiente y nos facilita las causas para terminar nuestro trabajo, pues este libro es muy abstruso bien por culpa de la traducción o porque Aristóteles mismo así se lo proponía. No hemos encontrado que ninguno de los comentadores tenga un comentario, ni literal ni del contenido, excepto lo contenido en el Libro de la curación por Avicena, y el libro que nos ha llegado está muy confuso. Si alguien estudia este libro nuẹstro y ve que en mis palabras falta algo que debe estar, o que organiza نســـ algo de manera distinta a la que se propone, que me perdone ${ }^{47}$.

El estilo demuestra la autenticidad del texto de Averroes, cuya franqueza y humildad aparecen en otros lugares. El taljịs ideal organiza la materia como un tronco que se divide en ramas, y las distintas tesis son reforzadas mediante demostraciones. Este modelo ideal se realiza en algunos casos; en otros, bien porque el material no se presta a ello, porque sus conocimientos o su tiempo no se lo permiten, «parafrasea» el texto aristotélico.

El que hayamos examinado primero sus taläjịs al Organon responde a una concepción de la lógica como arte independiente de la filosofia propiamente dicha, previa a ésta, opinión que Averroes comparte. No responde a un criterio cronológico, pues hemos leído que el taljị de las Categorías era posterior a otros, y probablemente el de los Tópicos sea el primero. De acuerdo con este criterio temático, siguen sus paráfrasis de la Retórica y de la Poética. Țodroș Ṭodroșī tradujo ambas del árabe al hebreo (Arles, 1337) ${ }^{48}$, y a partir de su texto de la $R e$ tórica, Abraham de Balmes hizo la traducción al latín impresa en la edición Iuntina ${ }^{49}$. M. Blaustein ve que Averroes tiene una concepción de la retórica como forma de discurso lógico, lejos de la preocupación aristotélica por el contexto político de este arte ${ }^{50}$. Es cierto que la paráfrasis se convierte en un tratado más bien teórico, pero Averroes no olvida la aplicación práctica. Allí donde Aristóteles habla de las tres clases de retórica según las tres clases de auditorio: el miembro de la

${ }^{47}$ Taljị̦ kitāb al-safsața, ed. Jéhamy, 729: 9-16.

${ }^{48}$ Steinschneider, M. Die hebraeischen Übersetzungen, 62-65.

${ }^{49}$ Secundum Volumen. Aristotelis De Rhetorica et Poetica Libri I, cum Averrois in eosdem paraphrasibvs, Venecia: apvd Iunctas, 1562, fols. 69-156.

${ }^{50}$ «The Scope and Methods of Rhetoric in Averroes' Middle Commentary on Aristotle's Rhetoric», en C.E. Butterworth (ed.), The Political Aspects of Islamic Philosophy. Essays in Honor of Muhsin S. Mahdi, Cambridge, Mass. 1992, 262-303. 
asamblea, que delibera sobre acciones futuras; el juez, dikastê, que resuelve sobre cuestiones pasadas, y el espectador, como crítico del actor. Averroes adapta: el miembro de la asamblea se convierte en el soberano (príncipe, ra'iss) y es el juzgador (häkim) del futuro, mientras el juzgador del presente «es aquél que el príncipe nombra, por ejemplo el cadí en nuestras ciudades, las ciudades del islam», y el espectador se concentra en la capacidad retórica del actor ${ }^{51}$. El soberano y el cadí musulmanes encuentran su lugar.

De la paráfrasis de la Poética existe ya traducción latina a partir del árabe, por Hermann el Alemán, terminada el 17 de marzo 1256 52. Todroṣ Todroși omitió los ejemplos poéticos árabes, y su versión hebrea fue la base para la traducciones de Jacob Mantino Hispano Haebreo ${ }^{53}$ (sic) y Abraham de Balmes al latín. De todos modos, al lector latino le llegaron los elogios de Averroes a la poesía que cultivaban sus compatriotas en al-Andalus, porque su poesía era «natural», y contenía imitación, melodía, metro (o ritmo) a la vez, a diferencia de la poesía clásica árabe ${ }^{54}$. Son conocidas las dificultades de Averroes en entender dos géneros literarios griegos, la tragedia y la comedia, inexistentes en árabe ${ }^{55}$. Jacob Mantino, en pleno Renacimiento, sí los entendía y explica optima ars laudandi, id est, Tragoedia ${ }^{56}$.

A pesar de todo, la filosofía en sentido propio no empieza más que con la Física. El texto de su paráfrasis no se conserva en árabe, sí en hebreo, todavía en forma manuscrita. Al latín, y a partir del hebreo, Jacob Mantino (m. 1529) sólo pudo traducir los tres primeros libros, porque la muerte le impidió seguir su trabajo, según precisan los impresores venecianos ${ }^{57}$. Hay que matizar que en árabe se conserva la

${ }^{51}$ Taljịs al-jiṭāba, ed. Sālim, p. 52, con referencia a Aristóteles, Rhet., 1358 a 31 - b 8.

${ }^{52}$ La primera edición crítica es de William F. Boggess, Averrois Cordubensis Commentarium Medium in Aristotelis Poetriam. Chapel Hill NC, 1965. Cf. su artículo «Hermannus Alemannus' Latin Anthology of Arabic Poetry», Journal of the American Oriental Society 88 (1969), 657-670.

${ }^{53}$ Secundum Volumen, fols. 217 verso - 228 verso.

${ }^{54}$ Secundum Volumen, fol. 218 A-B (imitatio, harmonia, numerus); Taljịs kitāb $a l-s ̌ i$ ' $r$, ed. Butterworth-Harīdī, 57-58.

${ }^{55}$ Taljịs kitāb al-ši ' $r$, ed. Butterworth-Harīdī, 65-72.

${ }^{56}$ Secundum Volumen, fol. $219 \mathrm{H}$.

${ }^{57}$ Quartum volumen Aristotelis De physico avditv libri octo. Cvm Averrois Cordvbensis variis in eosdem commentariis, Venecia, 1562, folio. $456 \mathrm{M}$. 
sinopsis, editada y traducida al inglés por $\mathrm{Ma}^{\mathrm{c}}$ șūmī y reeditada por al- ${ }^{\mathrm{c}}$ Alawi ${ }^{58}$.La paráfrasis respeta los libros aristotélicos, maqāla, y divide cada uno en secciones, $\hat{y} u m l a$, que a su vez se dividen en capítulos, fasl. En la traducción latina, los términos son liber, summa, caput, aunque son traducción directa del hebreo ma'mar, kelal, perakh. La distribución es por tanto similar a la que tenemos en su taljiș de las Categorias - aunque allí, en lugar de ŷumla teníamos dos niveles: ŷu', comprendiendo qism - y responde al espíritu de la divisio textus.

Zerahya ben Yitshaq ben Shealtiel, originario de Barcelona, tradujo la paráfrasis en Roma en $1284^{59}$, y en 1316, Qalonimos ben Qalonimos la tradujo de nuevo, en Arles ${ }^{60}$. Las razones de una nueva traducción seis lustros más tarde podemos encontrarlas en las dificultades de comprensión del texto de Zerahya. He comprobado cómo su traducción del principio del libro VIII ${ }^{61}$ es muy diferente del mismo pasaje en la otra traducción, por Qalonimoș ben Qalonimoș ${ }^{62}$, pero que sobre todo es más difícil de entender que la de Qalonimoṣ. La traducción de éste presenta variantes que ya Steinschneider observó y que agrupó en dos «redacciones principales».

En cuanto a la fecha de redacción del original árabe, ésta varía según los manuscritos, pues oscila entre 1170 y 1190 . Con independencia de posibles errores de copia, hay que averiguar qué versiones hebreas corresponden a una primera redacción original, que se habría terminado en Sevilla el 1 raŷab 565 (21 marzo 1170) y cuáles a una versión revisada, a partir de $1184{ }^{63}$. Esta investigación está siendo

\footnotetext{
${ }^{58}$ M. S H. al-Ma ${ }^{c}$ sūmī había editado y traducido el texto en The Dacca University Studies 8 (1956), 67-98. Ŷamāl al-Dīn al-'Alawī: «Min taljịs al-samā' al-țabīì̀», Maŷallat Kulliyat al-Ādāb bi-Fäs, 7 (1983-84), 205-255; acerca de la fecha, ver p. 211.

${ }^{59}$ Steinschneider, M. Die hebraeischen Übersetzungen, 114.

${ }^{60} I d ., 114-116$.

${ }^{61}$ Manuscrito Oxford, Bodleian Library, Bodl. 601 (Neubauer 1386), fols. 119-112 vo.

${ }^{62}$ Ms. Oxford, Bodleian Library, Bodl. 609 (Neubauer 1380), fols. 79- 81.

${ }^{63}$ Así en ms. Oxford, Bodleian Library, Bodl. 609 (Neubauer 1380), fol. 99 recto, leemos la fecha de 565/1170, pero en la página anterior, fol. 98 verso, líneas 26-27, nos encontramos con una anotación final donde Averroes asegura que su propósito en este comentario es idéntico al de Abū Haamid [Algacel] en su obra Intenciones de los filósofos. Esta invocación a Algacel, muy respetado por los almohades, se explica en un momento desfavorable, es decir, en una revisión que sería posterior a la muerte del sultán Abū Ya'qūb en 1184, su protector, y es similar a la que encontramos en su revisión del epítome de la Física, Madrid, 1983, p. 8: 5-7.
} 
realizada por R. Glasner, Jerusalén, quien ha establecido dos versiones y otra que combina ambas.

Siguiendo el orden del corpus aristotélico habitual y aceptado ciegamente como auténtico por Averroes, vemos que Averroes tiene también un taljiș al De caelo, que se conserva en árabe, y fue editado por $\hat{Y}$. al- ${ }^{c} A l a w i \bar{i}{ }^{64}$. En su prefacio a la edición, al- ${ }^{\mathrm{c}}$ Alawī distingue dos etapas en la obra averroica: la primera fase comprende las $\hat{y} a w \bar{a} m i^{\mathrm{c}}$ y los taläjịs, la segunda, los šurüh y otros escritos ${ }^{65}$, pero más tarde en su mencionado escrito al-Matn al-rušdī es más detallado, distinguiendo siete fases ${ }^{66}$.

De manera parecida a la Física, Averroes estudia los cuatro libros del De caelo organizados (munhasarar) en divisiones, $\hat{y} u m l a$, partidas luego en $\mathrm{fasl}$, matlab, problemas -Averroes plantea entonces unas cuestiones - o qism, apartados. Dentro de ellos abundan también las citas no literales, parafrásticas, de Aristóteles anunciadas por qāla. Averroes utilizaba la traducción árabe de Abū l-Faraŷ [Ibn al-Ṭayyib] ${ }^{67}$. Pero además Averroes se hace eco de las opiniones de Ptolomeo ${ }^{68}$.

La edición de al-'Alawī se sustenta en dos manuscritos, A: Leiden, Universidad, Or. 2075 y B: Oxford, Bodleian Library, Hatton, or. 34 (Uri, 439), en caracteres hebreos. Este B, Oxford, contiene una anotación del propio Averroes, que en A, Leiden, figura todavía al margen, a propósito de las palabras de Aristóteles en De caelo III. 300b16301a20. Aristóteles argumenta en favor de un movimiento natural propio de cada cuerpo simple y refuta las opiniones de Leucipo y Demócrito, de Platón y de Empédocles. Averroes pone todo su esfuerzo en estructurar las palabras del maestro y concluye:

Estos son los aspectos más adecuados según los cuales se pueden interpretar las palabras de Aristóteles en este pasaje, el cual hemos examinado con todo detalle en nuestro comentario literal (šarḥ 'alà l-lafz̆) ${ }^{69}$.

${ }^{64}$ Taljīs al-samä' wa-l-'ālam, Fez, 1984.

${ }^{65} \mathrm{Id}$., 28-46.

${ }^{66}$ Ver el cuadro sinóptico, en p. 133. Además, al-'Alawī señala la audiencia con Abū Ya'qūb como el momento de paso de un estadio a otro en su proyecto filosófico de conjunto, pp. 218-211

67 «Et in translatione Albefagar est aliud exemplum...», Quintum volumen. Aristotelis De coelo... cvm Averrois Cordvbensis variis in eosdem commentariis, Venecia, apvd Ivnctas: 1562 , fol. $219 \mathrm{C}$.

${ }^{68}$ Taljịs al-samä' wa-l-'älam, 244, 272.

${ }^{69} \mathrm{Id}$., 300: 7-9. 
Se trata pues de una anotación a modo de revisión, y muy posterior a la fecha de primera redacción. ¿Cuándo fue ésta? Steinschneider ya leyó en el manuscrito de Oxford, y con dudas en el de Leiden, la fecha de terminación de raŷab 566, marzo 1171, en Sevilla ${ }^{70}$, de manera que Averroes habría completado este taljịs a continuación del de la Física. Shelomo ben Yoșef ben Ayyūb ha-Sefardī, un judío granadino, tradujo el texto en Beziers en 1269 al hebreo. Como traductor del árabe al latín se supone Michael Scot, Miguel el Escocés (m. $c a$. $1235)^{71}$. Paulo el Israelita reelaboraría su traducción para la imprenta veneciana de $1560-62{ }^{72}$.

Averroes sigue con el mismo procedimiento en el taljịs al De generatione et corruptione, de la que tenemos una edición póstuma de $\hat{Y}$. al- ${ }^{\mathrm{C}}$ Alawi ${ }^{73}$. Al final de ésta Averroes nos dice que lo terminó el último jueves de ŷumādā II, de 567, es decir, el 27 de febrero de $1172^{74}$, de manera que cumplía una agenda bien definida: Física en 1170 , De caelo en 1171, y ahora De generatione.

Michael Scot probablemente tradujo este taljị̦ del árabe al latin ${ }^{75}$. Existe una sola versión hebrea, la de Qalonimoș ben Qalonimoș, que es de 1136 y ha sido objeto de una edición crítica por S. Kurland ${ }^{76}$. Aunque Steinschneider creía que había otra traducción, por Zerahya ben Yitshaq, el mismo S. Kurland demostró que se trataba de una confusión con la traducción del texto aristotélico ${ }^{77}$.

Averroes completa su proyecto con el taljị de los Meteorologi$c a$, editado también por al- ${ }^{\mathrm{c}} \mathrm{Alawi \overline {1 }}{ }^{78}$. Una observación sobre un terremoto ocurrido en Córdoba y alrededores en ŷumādà I, 565 (enero

${ }^{70}$ Steinschneider, M. Die hebraeischen Übersetzungen., p. 128

${ }^{71}$ Id., p. 56 § a). Sobre Michael Scot: Charles H. Haskins, «Michael Scot in Spain», en Estudios eruditos in memoriam A. Bonilla y San Martín, vol. 2, Madrid, 1930, 129-134. Thorndike, L., History of Magic and Experimental Science, New York, 1923, capitulo 51.

${ }^{72}$ Quintum Volumen Aristotelis De coelo ... cum Averrois Cordvbensis variis in eosdem commentariis (Venecia, 1562), fols. 272-336, Averrois Cordvbensis in quatvor libros De coelo Aristotelis paraphrasis.

${ }^{73}$ Taljịs al-kawn wa-l-fasād, Beirut, 1995, y terminada por M. al-Miṣbāhịi.

${ }^{74} I d$., p. 134

${ }^{75}$ Averrois Cordubensi Commentarivm medivm in Aristotelis De generatione et corruptione libros, ed. de F.H. Fobes y S. Kurland, Cambdridge, Mass., 1956.

${ }^{76}$ Averrois Cordvubensis commentarium medium et epitome in Aristotelis De generatione et corruptione libros, Cambridge, Mass., 1958.

77 «An Unidentified Hebrew Translation of Aristotle's De Generatione et Corruptione», Proceedings of the American Academy of Jewish Research 5 (1933-34), 69-76.

${ }^{78}$ Taljị̦ al-ätāir al-čulwìya, Beirut, 1994. 
1170) ${ }^{79}$, cuando Averroes, según nos dice, se encontraba en Sevilla, nos asegura que la redacción de este taljis es posterior a esta fecha ${ }^{80}$. Como en las ŷawämi 'o sumas alude también al mismo terremoto pero lo sitúa en 566, un año más tarde ${ }^{81}$, podemos estimar la fecha de composición de la paráfrasis en 1172. En ésta, en dos ocasiones se refiere a las «sumas pequeñas», y en otra, a su libro De sensu et sensato, es decir, a su propio resumen, trabajos de una fase anterior a los taläjịs. (Está claro que la anotación del terremoto en las ŷawāmi " es posterior a la primera redacción de las «sumas» y pertenece a una revisión).

Michael Scot es el probable traductor del comentario medio, impreso siglos más tarde en Venecia, entre otras ediciones ${ }^{82}$. La versión hebrea por Qalonimoș ben Qalonimoș (en Arles, 1316) se conserva todavía en manuscritos ${ }^{83}$.

Con respecto al texto árabe de los Meteorologica utilizado por Averroes, no cabe duda de que es distinto del texto griego que ahora conocemos, y a veces opuesto. Averroes no acaba de estar convencido de la autenticidad del texto que tiene delante, pero no se atreve a rechazarlo. Por ejemplo, Aristóteles no dice que el hemisferio sur sea inhabitable ${ }^{84}$; en cambio, la copia que Averroes tenía establecía que el hemisferio sur no se divide en una zona habitable y otra inhabitable ${ }^{85}$, tema por lo demás de intensa discusión en su ambiente, como prueba el reciente estudio de Resianne Fontaine ${ }^{86}$. Averroes buscará

${ }^{79}$ «Ocurrieron grandes terremotos al salir el sol y al declinar el mediodía en la fecha del mes de ŷumāda al-ūlà [21 enero - 19 febrero 1170] del año que historiamos y en la ciudad de Andújar duraron varios días, hasta que casi desaparecieron y se los tragó la tierra; y continuaron después de esto en la ciudad de Córdoba, Granada y Sevilla, y en todo al-Andalus», Ibn Șāhịib al-Ṣalāt, al-Mann bi-l-imāma, ed. 'Abd al-Hādī al-Tāzī, Beirut, 1964, p. 397; traducción de A. Huici Miranda, Textos medievales 24, Valencia, 1969, 153. La noticia es recogida luego por Ibn 'Id̄ārī en su al-Bayān al-mugrib, ed. M.I. al-Kattānī et al., Beirut, 1985, p. 110. Traducción española de A. Huici Miranda en Ibn ${ }^{c} I d \overline{a r} \bar{i}$, Al-bayān al-mugrib. Nuevos fragmentos. Textos medievales 8, Valencia, 1963, 416-417.

${ }^{80}$ Taljịs al-ätāar al- ${ }^{-}$ulwìya, ed. S. Fadl Allah y S. Abdel Razik, Cairo, 1994, 131.

${ }^{81} \mathrm{Id}$., 44

${ }^{82}$ Quintum volumen. Aristotelis De coelo, De Gen. et Cor., Meteorologicorum, De Plantis cvm Averrois... (Venecia, 1562), fols. 400A-487B. Para las ediciones renacentistas, ver Hissette, $\mathrm{R}$. en su introducción a De interpretatione.

${ }^{83}$ Steinschneider, M. Die hebraeischen Übersetzungen., 138-139.

${ }^{84}$ Metereológica 362 a $31-$ b 9.

${ }^{85}$ Taljịs al-ätâr al- 'ulwìya, 111: 6-7.

${ }^{86}$ «Between Scorching Heat and Freezing Cold: Medieval Jewish Authors on the Inhabitated and Uninhabitated Parts of the Earth», Arabic Science and Philosophy 10 (2000) 101-137. 
una explicación al hecho de que sea inhabitable, diciendo que es una masa de agua, necesaria para equilibrar la parte de tierra del hemisferio norte. Aunque no se atreve a rechazar el texto, hace esta observación: «Estas son las palabras de Aristóteles sobre este tema, según la copia del texto que nos ha llegado»» ${ }^{87}$.

La estructura de su comentario es aquí distinta. Averroes no divide y subdivide, sino sigue el texto aristotélico, respeta sus capítulos, y como mucho introduce dentro de ellos 'exposiciones' qawl. La originalidad la encontramos más bien en este procedimiento: después de resumir a Aristóteles, discute y se extiende sobre alguna cuestión. Por ejemplo, cuando termina la paráfrasis del texto 338 a $20-341$ a 37 , dice:

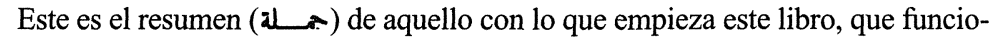
na a modo de introducción y de fundamentos de aquello que quiere tratar. Conviene ahora que investiguemos dos cosas: primera, lo que dice Alejandro [de Afrodisia] en el tema del fuego... y segunda, lo que suelen hacer los comentadores de este libro y del De caelo, de atribuir el calentamiento de los astros a otra causa, diferente de la causa del movimiento, que es la que Aristóteles atribuye en este libro ${ }^{88}$.

Averroes inicia así un excurso, y al terminarlo regresa al proceso de paráfrasis. Como en otros comentarios de este período, es decir, taläjiș, Alejandro de Afrodisia ${ }^{89}$ desempeña un papel principal en su interpretación. Hablando de los vientos y buscando la causa por la cual los vientos septentrionales y meridionales son más frecuentes que los occidentales y orientales, Averroes se encuentra con dos opiniones ${ }^{90}$ : la de Aristóteles "según el texto que nos ha llegado», y la de Alejandro de Afrodisia.

El texto atribuido a Aristóteles afirma que en las regiones E-W llueve más, y soplan menos vientos porque las lluvias obstaculizan los vientos. Añade que la exhalación procedente de las regiones $\mathrm{N}-\mathrm{S}$ es menor, y no se condensa, no llega a convertirse en agua, solamente es viento ${ }^{91}$. Ahora bien, según el texto griego, Aristóteles pensaba que las lluvias son opuestas a los vientos (Meteorológica II.4, 361 a 2-4), pero que donde llueve más es en las regiones N-S y da como ra-

${ }^{87}$ Taljīs al-ātār al-'ulwīya, 111: 8-9.

88 Id., 27: 7-15.

${ }^{89}$ Averroes llama ahora taljịs al comentario de Alejandro: Id., 101: 9.

${ }^{90}$ Id. $100-103$.

${ }^{91}$ Id., 100: 20-101: 2. 
zón de que, en contra de lo que acaba de decir, haya más vientos N-S el hecho de que hay más exhalaciones de humedad... exhalaciones que son los vientos (Meteorologica II.4 361 a 5-18).

Alejandro - según Averroes- sostiene que las regiones E-W son secas y, a causa del calor, las exhalaciones allí se deshacen «antes de hacerse viento», mientras que las regiones $\mathrm{N}-\mathrm{S}$ son húmedas y las exhalaciones, que son los vientos, son más fuertes.

Averroes quiere resolver la dificultad: Aristóteles y Alejandro de Afrodisia coinciden en que el sol calienta más en las zonas E-W, pero difieren en cuanto a las consecuencias. Para Aristóteles, el calor hace que las exhalaciones se deshagan a causa de su concentración y, para Alejandro, el calor hace que las exhalaciones se deshagan a causa de su rarificación.

¿Cómo explicar dos efectos tan opuestos? Averroes ve la solución en la proporción entre el agente, el sol que da calor, y el paciente, la tierra que contiene la humedad. Cuando la proporción entre agente y paciente es a favor del primero, llueve menos (Alejandro), cuando es a favor del segundo, llueve más (Aristóteles). Si llueve más en las regiones más cercanas al sol, E-W, «el texto atribuido a Aristóteles» tiene razón y si llueve más en las lejanas, N-S, Alejandro la tiene. Por tanto, si Aristóteles tiene razón, los vientos N-S serán más fuertes, y si tiene razón Alejandro, los vientos E-W prevalecerán.

Sin embargo, Averroes no sabe en qué dirección soplan más fuertes los vientos. En la península ibérica, la «isla de al-Andalus» los vientos son igualmente fuertes en las cuatro direcciones, aunque puede que los vientos del este y del oeste sean más frecuentes en la mitad oriental y occidental, respectivamente, pero Averroes piensa que la causa es la situación de la península, rodeada de mar.

Su taljịs a los Meteorologica contiene ésta y otras interesantes observaciones, que ya llamaron la atención de M. Alonso ${ }^{92}$. La latitud de Córdoba la establece en $38^{\circ}$ y medio ${ }^{93}$ (casi exacta, $38^{\circ}$ ). Uno de los pasajes más curiosos es aquél en que Averroes habla de la influencia del clima en el carácter de los habitantes. Conocíamos el pasaje de la edición latina, el clima de al-Andalus influye positivamente en sus habitantes, aunque sean inmigrados, y Averroes observa que «los hi-

92 «Averroes, observador de la naturaleza», en Teología de Averroes 1947. Reed. Sevilla, 1998, 25-41.

${ }^{93}$ Taljịs al-ätâr al-'ulwìya, 115: 16-17. 
jos de los árabes y de los bárbaros» ${ }^{94}$ se asimilan y llegan a destacar en el cultivo de las ciencias. Gracias a la edición de al-'Alawī, vemos que se refiere a los hijos de los árabes y de los beréberes, quienes «se desarrollan en la naturaleza de la nación a la que están vinculados, que es la de los españoles» إنسبانيون 95 . El país es la península de al-Andalus, pero los habitantes son los hispanos.

Con los Meteorologica se cierra un conjunto temático apuntado por el mismo Aristóteles ${ }^{96}$ y que Averroes repite casi literalmente al comienzo de su paráfrasis ${ }^{97}$, y a ellos les sigue el De anima. El alma es el principio de vida, vegetal y animal, y los libros sobre las plantas y los animales son continuación necesaria del De anima. En cuanto al taljị de Averroes sobre el mismo, que se ha conservado en árabe, Alfred Ivry lo ha editado ${ }^{98}$ en base a los dos manuscritos judeo-árabes conservados y con ayuda de un número considerable de manuscritos conteniendo la doble traducción hebrea ${ }^{99}$ : una primera por el tortosino Shem Țov ben Yitshaq, otra posterior por Moshe ben Tibbon (siglo XIII). La traducción de M. ben Tibbon recoge como fecha de redacción por Averroes el mes de ŷumādà I 577, que empezó el 12 septiembre 1181. La fecha resulta tardía, y hace pensar en un error del copista, en vez de 567/ 1172 que encaja perfectamente. Ivry encontró también esta fecha, 567/1172, más conforme al proyecto de los taläjīs, y propia de la primera redacción, redacción que no está representada ni en árabe ni en hébreo. También $\mathrm{M}$. Alonso pensaba en esta fecha, $1173{ }^{100}$. No hay que olvidar que Averroes en su taljịs de la Ética a Nicomaco, que es de 1177, hace referencia a su propio libro Acerca del alma ${ }^{101}$.

Por otra parte, 1181 es temprano para una segunda redacción, cuya existencia conocemos por frases del propio Averroes aludiendo dentro del taljiș a su comentario mayor. Por ejemplo, Averroes trata de las «formas imaginadas» y de las «intenciones imaginadas», y pre-

${ }^{94}$ Qvintum volumen... Meteorologicorum, fol. 436 A-B.

${ }^{95}$ Taljị̦ al-äțār al-'ulwìya, 104: 8-9.

${ }^{96}$ Meteorologica. 338 a $20-338$ b 1.

${ }^{97}$ Talīiș al-ätār al- 'ulwìya, 17-18.

${ }^{98}$ Taljīs kitäb al-nafs, Cairo, 1994.

${ }^{99}$ Steinschneider, M. Die hebraeischen Übersetzugen, 148-149.

${ }^{100}$ Teología de Averroes, 84-85.

${ }^{101}$ Tertium Volumen. Aristotelis Stagiritae libri Moralem totam Philosophiam complectentes, cvm Averrrois Cordvbensis in Moralia Nichomachia expositione, Venetiis apvd Ivnctas, 1562, fol. 153E: vt aestimo in libro de Anima. 
cisa: «Este significado lo hemos aclarado perfectamente en el comentario, šarḥ, a las palabras de Aristóteles en este capítulo» ${ }^{102}$.

Averroes estructura su paráfrasis en tres libros, que corresponden a los de la obra de Aristóteles. Su primer libro no tiene subdivisiones, está consagrado a las opiniones de los antecesores a Aristóteles; el segundo se divide en siete «exposiciones» qawl / aqwäl dedicadas una a la potencia nutritiva, otra a los sentidos en general y otras cinco a los sendos sentidos; el tercero igualmente está dividido en cuatro "exposiciones»: sobre el sentido común, la potencia imaginativa, la potencia racional y la potencia del deseo $n u z \bar{u}^{c} \bar{\imath} y a$, aquélla por la cual el hombre y el animal «se mueven hacia el placer presente» ${ }^{103}$. Cierra el comentario un capítulo fașl que parafrasea de De anima 434 a 22 hasta el final.

Averroes sigue la costumbre de intercalar frases de Aristóteles, que introduce con el término «dice». Siempre que le es posible presenta los argumentos en silogismos. En su tratamiento, en especial, del intelecto material dentro de la facultad racional, Averroes se hace eco del comentario de Alejandro de Afrodisia ${ }^{104}$ y suscribe su opinión de que el intelecto material es una disposición o potencia generada y que se destruye. Ahora bien, en este mismo taljiș, cambia de opinión ${ }^{105}$, pues también tiene en cuenta la doctrina de Temistio ${ }^{106}$, según la cual el entendimiento material es una sustancia eterna, y dice:

\footnotetext{
Con esto te han quedado claras las dos opiniones a la vez, la opinión de Alejandro y la opinión de otro [Avempace], y te ha quedado claro que la verdad, que es la opinión de Aristóteles, consiste en combinar las dos de la manera que hemos dicho... Puesto que esto está aclarado, volvamos a la exposición (taljīs) de todo lo que dice Aristóteles al respecto ${ }^{107}$.
}

Pienso que en la primera redacción de este taljịs Averroes no había tenido acceso, en cambio, al citado comentario de Temistio y que

${ }^{102}$ Taljīs kitäb al-nafs, 24: 5.

${ }^{103}$ Id., 143: 3-4. Cf. Aristóteles, tò orektikón, De anima, 433 b 11.

${ }^{104}$ De anima liber cum Mantissa, ed. Ivo Bruns, Berlin, 1887. Supp. Arist. II.1.

${ }^{105}$ Para H.A. Davidson se trata sin ninguna duda de un excurso: Alfarabi, Avicenna, and Averroes, on Intellect, Oxford, 1992, 276-281.

${ }^{106}$ In Aristotelis de anima paraphrasis, ed. Heinze, Berlín, 1899, Commentaria in Aristotelem Graeca 5.3. Partial Arabic text: The Arabic Version of Themistius "De ani$m a "$, ed. M.C. Lyons, Londres, 1973.

${ }^{107}$ Taljịs kitāb al-nafs, 125: 4-10. 
en la revisión que hace en la década de los 80 , introduce este excurso. Pero además Temistio le guía en su análisis del tercer intelecto, el llamado intelecto especulativo, el yo efectivo:

\footnotetext{
Conviene que sepas que Temistio y la mayoría de los comentadores piensan que el entendimiento que está en nosotros está compuesto del entendimiento que está en potencia y del entendimiento que está en acto, o sea, activo... [Temistio y Teofrasto] interpretan así las palabras de Aristóteles, tal como hemos demostrado en nuestro comentario šarh a las mismas. ${ }^{108}$
}

El pasaje es otra prueba de que Averroes revisó su taljị̦ cuando ya había compuesto su comentario mayor šarh , donde, en efecto, acepta en parte la explicación de Temistio ${ }^{109}$. La primera redacción de este taljiș la hace bajo la influencia del comentario de Alejandro de Afrodisia, en la revisión o revisiones, se aleja de él y se acerca a Temistio, sin perder nunca por ello su admiración por Alejandro...

Con la paráfrasis de la Metafisica se cierra el círculo que comprende la filosofia teorética, aunque entre De anima y ésta se sitúan los libros de los Animales, analizados también por Averroes. Pasemos, sin embargo, al taljịs de la Metafisica, cuyo original árabe no se ha conservado, pero del que existen dos traducciones hebreas: una por Zerahya ben Yitshaq ben Shealtiel (en Roma, 1284), y otra por Qalonimoṣ ben Qalonimos, de $1317^{110}$. En estas versiones hebreas, los libros de la $\mathrm{Me}$ tafisica explicados son trece. Averroes omite comentar el primer libro, el álpha meízon, empieza por el II, álpha élatton, y termina en el libro XIV, Ny que para él es por tanto el XIII de «su» Metafisica. En cuanto al estilo, falta una arquitectura de subdivisiones, y predominan los párrafos abiertos con un qäla/amar seguidos de pasajes selectos del texto aristotélico, que luego comenta. Conocemos el procedimiento de su taljị del De anima o del De caelo, pero en la Metafisica se aproxima más al que sigue en sus «grandes» comentarios.

En su comentario al libro Zeta, que lleva el número VI (VII en Aristóteles) podemos apreciar estas características, como revela el mismo inicio (Met. 1028 a 10-15):

108 Taljị̦ kitāb al-nafs, 130: 15-131: 4. Cf. Themistii in Aristotelis De Anima paraphrasis, ed. R. Heinze, Berlín, 1899, 99; trad. inglesa de Robert B. Todd, Two Greek Aristotelian Commentators on the Intellect, Toronto, 1990, 90.

${ }^{109}$ Ver infra p. 42

${ }^{110}$ Steinschneider, Die hebraeischen Übersetzungen, 160-167. 
Lo existente y el ente designan muchas especies, según las distinciones que hemos hecho en el libro precedente. Entre ellas está la que designa lo que es la cosa concreta, la cual no está en un sustrato; entre ellas está lo que designa la cualidad o cantidad concretas, $u$ otra de las cosas qué no expresan qué es la cosa concreta, la cual no está en un sustrato, y qué son las otras nueve categorías. Si esto es así, es evidente que lo existente y el ente primarios entre ellas (quiero decir las anteriores) son los que designan qué es la cosa concreta, la cual no está en un sustrato, puesto que ellos designan su sustancia ${ }^{111}$.

A primera vista, Averroes no hace más que repetir a Aristóteles, y las diferencias que puedan llamar la atención son terminológicas; nimtsa' es traducción fiel de árabe mawŷüd, que es la forma de traducir tò ón que se impone, mientras las primeras traducciones daban huwiya, convertida al abstracto hayūt, en hebreo. Sin embargo, Averroes introduce su propia lectura, porque relaciona de inmediato este libro con el de las Categorías, y donde la sustancia sensible tiene la primacía en el ser. A lo largo de su paráfrasis, Averroes mencionará otra sustancia que merece el nombre con más justicia, la sustancia separada, y una vez más la teología se integrará en su obra.

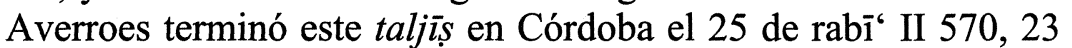
noviembre 1174 , dos años después de terminar la paráfrasis del $D e$ anima; pero sabemos más, pues al final del libro XI, que por tanto es el XII de la Metafisica, Averroes nos cuenta:

Aquí ha terminado mi tratamiento de este libro [Lamed]. Cuando escribía parte del mismo, ya padecía aquella enfermedad que todavía me aflige, y ruego a Dios que me haga vencerla. Como las circunstancias se han alargado, de modo que no he terminado la obra [entera], me he esforzado y limitado a investigar el misterio mencionado y lo he acabado confiando en que Dios me recompense por ello. Mi preocupación era porque este libro [Lamed] no conseguía proporcionar el beneficio de la obra [metafisica], aun cuando este libro es el que apunta a esta sabiduría y a su fruto. Aunque Temistio ya ha escrito sobre él, yo espero que mis palabras sean mejores, más claras para mis contemporáneos, y más cercanas a lo que dice el Sabio [Aristóteles]. Pido a Dios su ayuda y el bien de la recompensa. Terminé de escribirlo el día 9 del mes de șafar 570 de la era ismaelí ${ }^{112}$.

Averroes no estaba seguro de vivir para terminar su paráfrasis y es la primera vez que hace esta confesión. Se ha esforzado en terminar el

${ }^{111}$ Roma, Biblioteca Regia Casanatense, ms. 3083, fol. 45 ro , líneas 11-19.

112 Roma, Casanatense, fol. 120 recto, líneas 12-19. 
libro $L \bar{a} m$, pues considera que hasta entonces no era bien entendido, a pesar de que es la culminación de la sabiduría aristotélica.

El 9 de șafar 570 coincidía con el 9 de septiembre de 1174, de modo que en dos meses hizo la paráfrasis de los dos últimos libros, $M$ y $N$. Al final del libro XII ${ }^{113}$ y también del XIII (XIII y XIV de la $\mathrm{Me}$ tafisica de Aristóteles, respectivamente), aparecen también confesiones similares. Así leemos:

Si el Señor alarga mi vida, volveré a esta obra [Metafisica] y a otras para comentarlas (le-pharšam] palabra por palabra ${ }^{114}$ porque a nosotros no nos ha llegado un comentario tal de las mismas, y lo preparemos para que sea una ayuda para aquél que acuda a ellas, $\mathrm{y}$ también útil ${ }^{115}$.

En efecto, el Señor le dio suficiente vida para llevar a cabo la segunda parte de su proyecto: los comentarios «palabra por palabra». Antes de empezar éstos, creo que Averroes completó las paráfrasis de las obras lógicas. Hemos visto que su exposición de la Retórica lleva fecha de 26 de julio $1175^{116}$, y que al principio de la de las Categoría alude a su «costumbre» en las paráfrasis.

La Metafísica es la coronación de la filosofía teorética, pero en Aristóteles la filosofía práctica también se refleja en escritos que Averroes conocía en parte. Conocía la Ética a Nicómaco y la analizó en su paráfrasis acabada el jueves 4 de dū l-qa'da 572 (5 de mayo de 1177) ${ }^{117}$. Aunque en árabe no se conservan más que unos pocos fragmentos ${ }^{118}$, la traducción latina de Hermann el Alemán es completa. Esta traducción, a partir del árabe, fue hecha en Toledo en 1260, y la recoge la edición Iuntina ${ }^{119}$. De la traducción hebrea por Shemu'el ben Yehuda, de Marsella, y efectuada en 1321, existe una edición reciente del libro IV ${ }^{120}$.

\footnotetext{
${ }^{113}$ Roma, Casanatense, fol. 137 verso, 1. 3-17: "Si el Señor alarga mi vida".

${ }^{114}$ En árabe es šarh 'alà l-lafz, ver supra.

${ }^{115}$ Roma, Casanatense, fol. 143 verso, 1. 14- 16.

${ }^{116}$ Ver supra, nota 29.

117 Steinschneider, Die hebraeischen Übersetzungen, p. 216, calcula otra fecha: 27 mayo

${ }^{118}$ Berman, L.V., "Excerpts of the lost Arabic Original of Ibn Rushd's Middle Commentary on the Nichomachean Ethics", Oriens 20 (1967), 31-59.

119 Ver nota 82: Tertium volumen, fols. 1-160.

${ }^{120}$ The Hebrew Versions of Book Four of Averroes' Middle Commentary on the Nicomachean Ethics. L. V. Berman (ed.) Jerusalén, 1981. Ver también Steinschneider, Die hebraeischen Übersetzungen, pp. 217-219.
} 
Después de la Ética a Nicomaco, Averroes debía haber seguido con la Política, pero el mundo árabe no disponía de ella y utilizó en su lugar la República de Platón. La obra de Averroes, sin embargo, lleva el título de $\hat{y} a w \bar{a} m i^{c} \mathrm{y}$, en efecto, tiene más bien características de un epítome. Bien pensado, la Ética a Nicomaco es el mejor final posible para el proyecto de Averroes, en esta primera fase, en cuanto la filosofía adquirida en los tratados precedentes proporciona al hombre su felicidad máxima. En su comentario a Eth. Nic. X, 1177 a 5 - b 33 sobre el carácter contemplativo de la verdadera felicidad, Averroes refuerza la argumentación que la actividad intelectual es la mejor acción del ser humano, señalando que la continuidad en esta acción - frente a una acción momentánea- es la que hace posible la verdadera felicidad ${ }^{121}$.

Es indiscutible que en el período comprendido entre 1168 y 1177 Averroes estuvo ocupado en la confección de los taläjịs. Conociendo su método de proceder, sólo una vez terminados éstos, empezaría la redacción de los tafāsìr.

\section{Interpretar a Aristóteles}

Después que, de manera sistemática, Averrroes tomó todas las obras de Aristóteles y explicó su contenido en los talājịs, pasó a comentarlas «palabra por palabra». Hemos advertido su preocupación por vivir lo suficiente para terminar su tarea, y no debe sorprendernos que concentrara estos comentarios literales en unas cuantas obras que él consideraría más importantes. De todos los libros del Organon ${ }^{122}$ solamente conocemos su comentario literal a los Analíticos Posteriores, y en árabe, una parte del mismo. 'Abd al-Raḥmān Badawī publicó el comentario de Averroes al primer libro ${ }^{123}$, que es la parte conservada en los dos manuscritos conocidos: Leiden, Or. 2073 y

\footnotetext{
${ }^{121}$ Et patens est quod intellectus cuiusdam in nobis, et quod operatur quidem in scibilibus, quos comprehendit intellectus, et actio eius in ipsis continua est valde, et plus alijs ex caeteris actionibus potentiarum inuentarum in nobis è quod est intellectus. Et iam dictum est quod actio intellectus dignior est $v$ t sit continua quam vt sit agens in hora quadam, Tertivm volumen, fol. $153 \mathrm{E}$. tica.

${ }^{122}$ Recordemos que para Averroes la lógica comprende además la Retórica y la Poé-

${ }^{123}$ Šarh al-burhān li-Arisțū, Kuwait, 1984.
} 
Florencia, Laurenziana, LXXX, 54. La traducción hebrea es de Qalonimoṣ ben Qalonimoṣ (hecha en Avignon, diciembre 1314) ${ }^{124}$, y tres de los manuscritos contienen la fecha de redacción: dū l-ḥiŷŷa 575, mayo 1180. A partir del hebreo hicieron sus traducciones J. Francisco Burana ${ }^{125}$, Abraham ben Meir de Balmes y Jacob Mantino, todas las cuales aparecen, en columnas paralelas, en la edición veneciana de $1574^{126}$.

Recordemos que Averroes denomina los Segundos Analíticos, «libro del silogismo apodíctico» o «de la demostración». De acuerdo con las palabras de Aristóteles, un silogismo demostrativo exige que las premisas sean verdaderas, primeras, inmediatas, mejor conocidas y anteriores a la conclusión, y que sean sus causas (An. Post. $71 \mathrm{~b}$ 20-25).

El comentario a los Analíticos Posteriores se inicia con una extensa introducción donde Averroes nos aclara los objetivos del texto aristotélico, su utilidad, su orden entre los otros escritos, y sus partes. «El objetivo de este libro es el estudio de los silogismos apodícticos y de las definiciones» ${ }^{127}$. Los silogismos apodícticos - precisa-, desde el punto de vista de la forma, se estudian en los Analiticos Primeros y, desde el punto de vista de las «materias», en este libro.

¿Escribió Averroes también un tafsir de los Primeros Analíticos? Parecería lógico, y tenemos una indicación del propio Averroes diciendo «Qué significa Analíticos ya se ha explicado en el šarh del $\mathrm{Li}$ bro del silogismo» ${ }^{128}$. Sin embargo, no está claro que Averroes utilice aquí šarh en sentido preciso, y puede que se esté refiriendo al comentario medio.

El beneficio del libro es el conocimiento de la verdad, como es beneficio de todo el arte de la lógica ${ }^{129}$. Dado que la filosofía es conocimiento científico en cuanto se construye sobre silogismos apodícticos —al menos ésta es la aspiración de Averroes-y con ayuda de defi-

\footnotetext{
${ }^{124}$ Steinschneider, Die hebräischen Übersetzungen, p. 95. Qalonimoṣ murió en Avignon poco después.

${ }^{125}$ Steinschneider, ibid. sospecha que este profesor de Verona se apropió de la traducción de otro, algún judío, pues no se le conocen más traducciones.

${ }^{126}$ Primi Voluminis pars II. Aristotelis... Posteriorum Resolutionum libri duo cvm Averrois... magnis commentariis triplici interpretatione distinctis. La traducción de Mantino es incompleta, morte praeuentus, fol. $319 \mathrm{~B}$.

${ }^{127}$ Šarh al-burhān, 157: 8.

${ }^{128}$ Id., 157: 14.

${ }^{129}$ Id., 160: 3.
} 
niciones, el libro de la Demostración es esencial tanto en la determinación de los materiales de estos silogismos, en la medida en que «infunden certeza», no en cuanto son «un ente», como en la determinación de las definiciones en la medida en que proporcionan «un concepto completo», no porque sean «un ente». Completando esto, el libro de la Demostración estudia los silogismos apodícticos y las definiciones en cuanto son «generales» y «comunes», no particulares a cada ciencia:

El estudio por Aristóteles, en este libro, de los silogismos apodícticos y de las definiciones no termina en las diferencias específicas últimas de cada ciencia, porque lo que es específico de cada ciencia, Aristóteles suele mencionarlo al comienzo de dicha ciencia, tal como hizo en la Física y en el libro undécimo de los Animales ${ }^{130}$. Aquí solamente menciona las diferencias generales y próximas, dejando las últimas para aquellas ciencias. Por esto Aristóteles, en este libro, no incluye ningún capítulo que trate de cómo aplicar estos silogismos apodícticos y definiciones a las ciencias, tal como hizo Alfarabi ${ }^{131}$.

Está claro hasta dónde llega la ciencia de la lógica: a las características generales del conocimiento demostrativo, no de cada ciencia. En esto discrepa de Alfarabi, al que en otros tiempos seguía ${ }^{132}$, y no es el único lugar en que lo hace. Averroes cree que, simplemente, Alfarabi no llegó a entender a Aristóteles ${ }^{133}$ y tampoco Avicena ni Avempace reciben su aprobación. De entre los comentarios griegos, sólo tiene a su alcance el de Temistio ${ }^{134}$, no el de Alejandro de Afrodisia, aunque piensa que deben coincidir ${ }^{135}$.

A pesar de reducir el ámbito que abarca la ciencia en sí del silogismo apodíctico, o demostrativo, y de la definición, Averroes no renuncia al ideal de aplicar estos dos instrumentos a todas las ramas de la filosofía.

\footnotetext{
${ }^{130}$ A. de Balmes y J. Mantino rectifican: in Primo de Partibus animalium, y Balmes incluso precisa: ca. 1 (Part. Anim. 639 a 1- 646 a 6). Primi Voluminis parts II, fol. 3 E.

131 Sarh al-burhān, 159: 2-8.

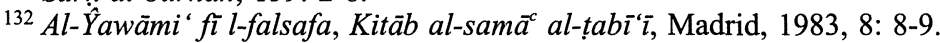

${ }^{133}$ Huius autem totius causa fuit defectus attingendi mentem Aristotelis. Primi voluminis pars II, fol. $455 \mathrm{~F}$.

${ }^{134}$ Analyticorum Posteriorum paraphrasis, ed. M. Wallies, Berlín, 1900. CiAG 5.1.

${ }^{135}$ Et licet nobis peruenerit huius viri interpretatio huius libri, tamen peruenit nobis expositio Themistii, qui quiem pro maiori parte non repugnat Alexandro. Primi voluminis pars II, fol. 429 A.
} 
La primera obra a la que puede aplicar su concepción sistemática, lógicamente demostrable, de la filosofía es la Física, de la que no se conserva ningún original árabe. La traducción hebrea es obra del mismo traductor responsable de la paráfrasis: Qalonimoș ben Qalonimoș, y se conserva todavía en manuscritos ${ }^{136}$. Michael Scot (m. 1235) es el probable autor de la traducción del árabe al latín, impresa en Venecia ${ }^{137}$ y en vías de edición crítica por H. Schmieja ${ }^{138}$. Piensa Schmieja que Herman el Alemán también hizo una traducción, conservada en un solo manuscrito.

En cuanto a la fecha de redacción del šarh, el hecho de que en 1180 hubiera terminado el de los Analitica Posteriora no supone necesariamente que sea posterior a éste, pero como en el período 1177-1180 Averrroes estuvo ocupado en varias obras ${ }^{139}$, es probable que así sea y se puede situar a partir de 1181 .

¿Cuáles son las diferencias específicas propias de la física? El prólogo que la edición veneciana nos ofrece en una doble versión ${ }^{140}$ nos dice primero que este libro es parte de la ciencia natural. La ciencia natural quiere conocer «las causas de las especies sensibles y las causas de los accidentes existentes en ellas» y en este contexto:

El objetivo de este libro es conocer las causas comunes a todos los seres naturales, tales como la materia, la forma, la finalidad y el agente, así como conocer aquellas causas primeras que se puedan conocer en esta ciencia, como son la materia prima y el primer motor. Sin embargo, la forma primera y la finalidad son objeto de estudio por el metafísico ${ }^{141}$.

Igual que hacía al principio de su comentario a los Analíticos posteriores, aquí, al principio de la Física, Averroes define también su utilidad, su orden entre los otros escritos, y sus partes. En este proe-

${ }^{136}$ Steinschneider, Die hebraeischen Übersetzungen, 122-124.

${ }^{137}$ Quartum volumen Aristotelis De physico avditv libri octo. Cum Averrois Cordvbensis variis in eosdem commentariis, apvd Ivnctas, 1562.

138 «Secundum aliam translationem: Ein Beitrag zur arabisch-lateinischen Übersetzungen des grossen Physikkomentars von Averroes», Averroes and the Aristotelian Tradition, 316-336.

1391177 , comentario a la Ética Nic., 1178, De substantia orbis, en Marrakesh, y 1179-80, Pruebas de las creencias religiosas, en Sevilla.

${ }^{140}$ Una probablemente de M. Scot, del árabe, y otra de J. Mantino, a partir del hebreo. Existe una traducción hebraico-inglesa por S. Harvey: «The Hebrew Translation of Averroes' Proemium to his Long Commentary on Aristotle's Physics», Proceedings of the American Academy for Jewish Research, 52 (1985), 55-84.

${ }^{141}$ Quartum volumen, fol.1 C-G. 
mio leemos que el beneficio de la Física es parte del beneficio de las ciencias especulativas, y éstas constituyen la perfección del hombre. Hay una secuencia natural: la perfección del hombre es sabiduría, es decir, conocimiento universal especulativo. Adquirida esta ciencia, el hombre encuentra su felicidad y una vida eterna ${ }^{142}$. Así hablaba Alfarabi o su predecesor Avempace.

Además, Averroes hace referencia a Alejandro de Afrodisia y a su prólogo, que no nos ha llegado; el sabio, consciente de la brevedad de la vida y de que la materia está en el origen de los males, no temería la muerte. Solamente después de ella puede alcanzar la perfección ${ }^{143}$.

Para Averroes, sin embargo, la referencia a Alejandro no es aquí lo más importante e insiste en que la práctica misma de la ciencia de la naturaleza y de la ciencia divina, es decir, metafísica, es perfección, y que este libro, la Física, comprende los principios y fundamentos de los que trata el filósofo de la naturaleza ${ }^{144}$.

Debes saber que el objeto de este libro (Física) es la naturaleza y los principios naturales en cuanto son comunes a todas las cosas naturales, y por tanto en este libro (Aristóteles) no definió el cuerpo ni otras cosas cosas que estudia el filósofo de la naturaleza, como lo hizo al comienzo del De caelo et mundo. ${ }^{145}$

En su interpretación, Averroes se apoya en los comentarios de Alejandro de Afrodisia y de Temistio ${ }^{146}$, aunque con el segundo suele discrepar. Rechaza siempre las opiniones de Avicena, empezando por la que afecta a la esencia misma de la ontología aviceniana, y que dice que es tarea del filósofo primero, el teólogo, demostrar la existencia del Primer Principio ${ }^{147}$. Asimismo manifiesta su distanciamiento de Avempace, al que otrora había seguido ${ }^{148}$, y quien está detrás de las opiniones de Avempace es a menudo Juan Filopón o el Gramático, como ha demostrado el trabajo de P. Lettinck ${ }^{149}$, pero Averroes rara vez lo menciona.

142 Quartum volumen, fol. $1 \mathrm{H}$

${ }^{143}$ Id., fol. 2 A- F: cum sciuerit quod perfectionem habere non potest, erit ei mors praeeligenda super vitam.

${ }^{144}$ Id., fol. 4 B: iste liber comprehendit res quae sunt principia et radices universales illorum de quibus vult alloqui naturalis.

${ }^{145} \mathrm{Id}$., fol. 49 I-K.

${ }^{146}$ In Aristotelis Physica paraphrasis, ed. H. Schenkl, Berlin, 1900. CiAG 5.2.

${ }^{147}$ Quartum volumen, fol. 47 G: quod primus Philosophus demonstrat primum principium esse. Cfr. fol. $340 \mathrm{E}$.

${ }^{148}$ Id., fol. 266 C: ego autem diu sustinui oponionem Auempace.

${ }^{149}$ Aristotle's Physics and its Reception in the Arabic World, Leiden, 1994. 
La ocasión más significativa en la que menciona a Juan el Gramático es al comienzo del libro VIII. Aristóteles da una doble interpretación del pasaje aristotélico Physico VIII.1, 251 a 10 - b 10, argumentando en favor de la eternidad del movimiento. Para Averroes, Juan el Gramático sería el responsable de la primera interpretación ${ }^{150}$, que para él no es correcta y que influyó en Alfarabi.

Según acabamos de oírle a Averroes, el libro De caelo trata ya de diferencias o características específicas, y no comunes a todos los seres naturales. El šarh de Averroes se conserva parcialmente en árabe y G. Endress, que prepara la edición crítica, hace unos años publicó una edición facsímil ${ }^{151}$ que cubre una tercera parte. No conocemos ninguna traducción hebrea. Por suerte, la traducción latina de M. Scot es completa ${ }^{152}$, a no ser que le falte algún prólogo.

Sobre la fecha de composición, aunque encontramos en este tafsìr una referencia al compendio del Almagesto ${ }^{153}$, ésta no nos ayuda porque tal compendio es de primera época, hacia $1159{ }^{154}$. En cambio, más útiles son las referencias a su comentario mayor a la Física, ya recogidas por M. Alonso ${ }^{155}$. Como Alonso situaba la composición del tafsir de la Física en 1186, propuso el año 1188 para la del De caelo. Acabo de sugerir 1181 para el tafsìr de la Física, de manera que también al del De caelo le corresponderá una fecha anterior.

Averroes se queja de las dificultades de la traducción árabe de Aristóteles, traducción que considera que es de al-Kindī, aunque este filósofo encargaba las traducciones a otros: «pues no tenemos más que la traducción de al-Kindī; sin embargo, las traducciones de Isḥāq [Ibn Ḥunayn] son más fieles» ${ }^{156}$.

\footnotetext{
${ }^{150}$ Quartum volumen, fol. 341 A: Ioannes Grammaticus, et existimauit quod quaedam potentiarum inuenitur cum illo ad quod est potentia...

${ }^{151}$ Commentary on Aristotle's Book on the Heaven and the Universe, Frankfurt am Main, 1994.

${ }^{152}$ Quintum volumen Aristotelis De coelo, De generatione et corruptione, Meteorologicorum, De plantis cvm Averrois Cordvbensis variis in eosdem commentariis, Venecia, apvd Ivnctas.

${ }_{153}^{15}$ Quintum volumen, fol. $138 \mathrm{E}$

154 Juliane Lay, «L'abrégé de l'Almageste: un inédit d'Averroès en version hebraïque», Arabic Science and Philosophy 6 (1996), 26.

${ }^{155}$ Teología de Averroes, 1947. Sevilla, 1998, 94-95.

${ }^{156}$ Nos enim non habemus nisi translationem Alkindi, translationes autem veriores sunt Isaac, Quintum volumen, fol. 203 A.
} 
Para su trabajo, Averroes tiene acceso al comentario de Temistio ${ }^{157}$, pero no al de Alejandro de Afrodisia, de manera que sus referencias a Alejandro son indirectas, a través del primero ${ }^{158}$. Como en otros comentarios literales, simpatiza más bien con Alejandro, mientras se opone casi siempre a Temistio. Si Temistio defiende a Platón y contradice a Aristóteles, Averroes no puede más que defender a Aristóteles y combatir a los dos, Platón y el neoplatónico Temistio. A propósito de De Caelo III 301 a $4-20$, Averroes toca una cuestión clave como es la creación del mundo:

todos los filósofos antiguos están de acuerdo en esto, en que es imposible afirmar algo hecho a partir de cosas inexistentes, a no ser que fuera posible que el no ser se convierta en ser, lo cual es imposible, y esto contradice del todo [la doctrina de] los legisladores [religiosos] ${ }^{159}$.

Sin embargo, Platón, en Timeo, 30 a, hablaba de una producción temporal del mundo donde el Demiurgo organiza el desorden, y Temistio le defiende ${ }^{160}$. Averroes parafrasea su defensa, que se centra en distinguir entre dos usos del término caos: «el desorden se dice de dos maneras, una es el no ser, otra es una disposición innatural» ${ }^{161}$. Temistio explica el desorden platónico como «materia privada de cualidad», algo que puede asimilar a la materia prima aristotélica. Averroes no acepta esta interpretación, «non est privatio» porque Platón nunca reconoció la materia prima ${ }^{162}$.

Dentro de la tradición filosófica árabe, no sólo Avicena, al que siempre ataca, sino también Alfarabi tienen un lugar en este comentario. Hemos mencionado el rechazo que manifiesta Averroes por Juan Filopón, cuyo texto no conoce directamente sino a través de Alfarabi. Así por medio de Alfarabi sabe que Juan el Gramático sostiene que el movimiento de los cuatro cuerpos simples es de la misma especie, lo

157 Themistii in libros Aristotelis de Caelo paraphrasis. Hebraice et latine, ed. S. Landauer, Berlin, 1902.

${ }^{158}$ Por ejemplo, iam dixit Themistius quod Alexander dixit, Quintum volumen, fol. 67 I. Alexander autem, secundum quod narrauit Themistius, explanat.., fol. $158 \mathrm{G}$.

${ }^{159}$ Et omnes Antiqui conueniunt in hoc, quam impossibile est vt ponatur factus ex rebus non entibus, nisi esset possibile vt non esse ipsius transmutaretur in esse quod es impossibile et est amxime contra eos qui ponebant leges, Quintum volumen, fol. $192 \mathrm{~K}$.

${ }^{160}$ De caelo paraphrasis, $166-167$.

161 Quintum volumen, fol. 193 C.

162 Plato nunquam percepit primam materiam, Quintum volumen, fol. 193 I. 
que rechaza Averroes ${ }^{163}$, señalado que sus lugares son distintos y así sus especies. El movimiento circular es el único que no se distingue de otro en cuanto a la especie. La oposición en el movimiento circular es un problema «muy difícil», como reconoció Alejandro de Afrodisia ${ }^{164}$, y tampoco Temistio aclaró el sentido de las palabras de Aristóteles en De caelo I, 271 a 29-33, diciendo que un movimiento circular excluye cualquier contrario. Antes que los editores modernos, Averroes vio las dificultades del pasaje, y cuyo texto es «sagrado»:

Estuve mucho tiempo sin entender la explicación última de este pasaje, pero Dios me hizo llegar a la verdad. De acuerdo con esta explicación [verdadera], Aristóteles quiere decir con sus palabras que el movimiento circular no tiene contrario, pero no en sí mismo, que es un movimiento separado de los cuerpos naturales, sino en cuanto está en un cuerpo movido por naturaleza ${ }^{165}$.

El movimiento circular y centrado en la tierra (in circuitu centri) tiene la primacía y todo el universo debería explicarse mediante el mismo. La realidad no es así, y las observaciones astronómicas forzaron explicaciones más ajustadas a sus resultados, pero distantes de este principio ideal. Averroes, que menciona a dos astrónomos árabes: Abū Ma‘šar al-Baljī (m. 886) ${ }^{166} \mathrm{y}$, probablemente, al-Hasan Ibn al-Haytam (m. 1041) ${ }^{167}$, conoce bien a Ptolomeo, su sistema de epiciclos y esferas eccéntricas y los distintos movimientos que atribuye a cada esfera celeste. Así Ptolomeo atribuye cinco movimientos a la luna, no tres, como hacían sus predecesores ${ }^{168}$, añade una novena esfera y encuentra en la esfera de las estrellas fijas - la octava - un movimiento retardatorio, que «los astrónomos árabes describen como un movimiento de precesión y recesión» ${ }^{169}$. Con razón, Averroes ve que el sistema de Ptolomeo está caracterizado por dos novedades:

\footnotetext{
${ }^{163}$ Quintum volumen, fol. 7 D-E.

164 Id., fol. $22 \mathrm{I}$.

${ }^{165}$ Ego autem longo tempore fecit moram, in quo non intellexi explanationem istius loci ultimam: sed Deus induxit me ad veritatem. Et secundum hanc explanationem erit intentio sermonis Aristotelis quod motus circularis non habet contrarium, non in eo, qui es motus abstractus a corporibus naturalibus, sed in quantum est in corpore moto secundum naturam, Quintum volumen, fol. $22 \mathrm{~K}$-L.

${ }^{166}$ Albumasar, Quintum volumen, fol. $17 \mathrm{G}, 104 \mathrm{~F}$.

${ }^{167}$ Auennatha in tractatu singulari, Quintum volumen, fol. $131 \mathrm{G}$.

${ }^{168}$ Antiqui opinabant ante Ptolomeum quod Luna habet tres motus... Ptolomaeus vero dedit Lunae alios duos motus, Quintum volumen, fol. $139 \mathrm{E}$.

${ }^{169}$ Moderni Arabes dicunt quod iste motus est motus antecessus et retrocessus, Quintum volumen, fol. $144 \mathrm{D}$.
} 
pues estos movimientos que afirma Ptolomeo se levantan sobre dos fundamentos que contradicen la ciencia de la naturaleza, a saber, el eccentro y el epiciclo, y los dos son falsos ${ }^{170}$.

Este no puede ser el sistema de Aristóteles, pero éste se limitaba a establecer que sólo el último cielo se mueve de manera uniforme y regular, y que los movimientos inferiores no reflejan ninguna unidad (De caelo II, 288 a 12 - 17). En su comentario al pasaje, Averroes rechaza la posibilidad de los epiciclos y de las esferas eccéntricas y sugiere un sistema donde los polos de una esfera se mueven, rotan, sobre los polos de otra. Este es su proyecto:

Si Dios nos da vida suficiente, investigaremos la astronomía que estaba en vigor en la época de Aristóteles, y se verá que aquélla no contradice a la física, y son los movimientos que Aristóteles denomina laulab ${ }^{171}$.

La línea leulebia de la que luego nos habla Averroes es una línea helicoidal, y bien puede ser un eco de la curva hipopeda que siguen los planetas en la teoría homocéntrica de Eudoxo ${ }^{172}$. Averroes no llevará a cabo su proyecto - ver infra-, pero tampoco Nür al-dīn al-Biṭrūŷi tendrá éxito en el suyo, basado en el principio de los polos rotando ${ }^{173}$.

El gran comentario de Averroes al De anima es el que más influencia tuvo en el mundo cristiano. Averroes debió de escribirlo después de su comentario a la Física, como observa Alonso ${ }^{174}$, por una clara referencia a éste. No conservamos ningún original árabe, y el manuscrito hebreo mencionado por Steinschneider ${ }^{175}$ es una traducción del latín, quizá del mismo 1475, fecha de su copia, según comprobó F. Stuart Crawford en su prólogo a la edición crítica de la tra-

${ }^{170}$ Isti enim motus, quos ponit Ptolomaeus fundantur super duo fundamenta, quae non conueniunt scientiae Naturali, scilicet, ecentricum et epicyclum, quorum utrumqve est falsum, Quintum volumen, fol. 140 L-M.

${ }_{171}$ Si Deus prolongauerit nobis vitam nos perscrutabimur de Astrologia, quae erat in tempore Aristotelis, videtur enim quod illa non contradicit physicae, et sunt motus, qui dicuntur laulab ab Aristotele..., Quintum volumen, fol. 119 A.

${ }_{172}$ Dreyer, J.L.E. A History of Astronomy from Thales to Kepler, 1906, Nueva York, 1953, 95-107.

${ }^{173}$ Alpetragius, ca 1150-1200, según la traducción latina de M. Scot, editada por Francis J. Carmody, Al-Bitrūügi, De motibus celorum, Berkeley, 1952. Cf. Bernard R. Goldstein, Al-Bitrüği: On the Principles of Astronomy, 2 vols., New Haven, Conn., 1971.

${ }_{174}$ Teología de Averroes, 95-96.

${ }^{175}$ Die hebräischen Übersetzungen, 151, se trata de Berlín, or. Fol. 1387. 
ducción latina ${ }^{176}$. Esta traducción latina es obra de Michael Scot, y se encuentra también en la edición de Venecia ${ }^{177}$.

La fama del gran comentario se debió sobre todo al planteamiento sobre la inmortalidad humana basado en su concepción del entendimiento material. Su comentario del Libro III empieza en De anima 429 a 10, y enseguida Averroes se extiende analizando el entendimiento material. Aquí se aleja de la interpretación de Alejandro de Afrodisia ${ }^{178}$, según la cual el entendimiento material era una potencia contingente, y entiende que tiene que ser una sustancia eterna, posición de Temistio ${ }^{179}$, et alios, que sin embargo no comparte totalmente:

así pues he creído oportuno escribir mi opinión al respecto. Aunque mi opinión no fuese perfecta, serviría como principio para la perfecta. De modo que ruego a los hermanos cuando vean este escrito, que escriban sus dudas y quizá así se encontrará la verdad, si todavía no la he encontrado ${ }^{180}$.

A lo largo de sus argumentos, no encontramos una preocupación por la inmortalidad del alma humana, sino que éstos se centran en la cuestión del conocimiento. Averroes mantiene, en relación con el tal$j i \bar{s}$, su doctrina de que el conocimiento intelectual es fruto de la actuación del entendimiento agente sobre el material, pero ahora es más detallado en sus explicaciones. Remitiendo al De sensu et sensato, distingue una facultad cognitiva en el hombre, previa a la racional, por tanto individual y perecedera. En ella, primero está el sentido común, luego la facultad imaginativa, luego la cogitativa, finalmente la memoria. Recientemente, R. Taylor ${ }^{181}$ ha analizado esta virtus cogi-

\footnotetext{
${ }^{176}$ Averrois Cordvbensis commentarivm magnvm in Aristotelis De anima libros. Cambridge, Mass., 1953; reimp. Túnez, 1997.

177 1562-1574, Suppl. II, Aristotelis De anima libri tres cum Averrois commentariis.

178 Tras citar literalmente un pasaje del De intellectu de Alejandro, afirma: Et ista opinio in substantia intellectus materiales maxime distat a verbis Aristotelis, Commentarivm magnvm, 395: 228.

179 Themistii in Aristotelis De anima paraphrasis, ed. R. Heinze, Berlin, 1899. CiAG 5.3. Cf. 99. Trad. árabe parcial editada por M. Lyons, The Arabic Version of Themistius "De Anima", Oxford, 1973, trad. inglesa Robert B. Todd, Themistius, On Aristotle's On the Soul. Cornell, 1996.

${ }^{180}$ Ideo visum est michi scribere quod videtur michi in hoc. Et si hoc quod apparet michi non fuerit completum, erit principium complementi. Et tunc rogo fratres videntes hoc scriptum scribere suas dubitationes, et forte per illud invenietur verum in hoc, si nondum inveni. Commentarium magnvm, 399: 362-367.

181 Taylor, R. C. «Remarks on Cogitatio in Averroes' Commentarium Magnum in Aristotelis De Anima libros», en Averroes and the Aristotelian Tradition, 217-255.
} 
tativa, la facultad que opera con la imaginación y elabora unas intentiones ymaginate, literalmente «significados imaginados». Detrás del término ymaginate está jayāli, adjetivo de tajayyul, traducción del griego phantasía, de manera que debemos decir «imaginativo»; detrás de intentio está el árabe $m a$ 'nà, la forma aprehendida sin relación con la materia. Así en el comentario medio leemos al-ma'ānī al-jayālìya ${ }^{182}$. Por su implicación material, la facultad cogitativa es no sólo individual, sino corporal ${ }^{183}$.

Conocemos mediante nuestra continuidad (o unión) con la forma aprehendida, es decir, «con aquella parte de las formas imaginativas que dentro de nosotros es casi como una forma, por así decir» ${ }^{184}$. Esto supone que el entendimiento agente «hace que los significados que hay en la facultad imaginativa pasen a mover el entendimiento material en acto» ${ }^{185}$. El entendimiento agente hace pasar estas intentiones de la potencia al acto, y entonces ellas actúan sobre el entendimiento material como motrices. El resultado son los inteligibles existentes en acto, que generan el llamado entendimiento teorético, intellectus speculativus ${ }^{186}$. Este entendimiento es un conjunto de conocimientos, perecederos a nivel individual, pero permanentes a nivel de la especie humana. La discrepancia con Temistio afecta a la naturaleza del intellectus speculativus:

Temistio pensaba que nosotros somos entendimiento agente y que el entendimiento especulativo no es más que la unión (continuatio) del entendimiento agente con el entendimiento material. Pero no es así como pensaba, sino que lo que hay que creer es que en el alma hay tres partes de entendimiento: una es el entendimiento receptivo; la otra, el eficiente; la tercera, el hecho. Dos son eter-

\footnotetext{
${ }^{182}$ Averroes' Middle Commentary on Aristotle's De anima, ed. A.L. Ivry, Cairo, 1994, 34: 3-5.

${ }_{183}$ Virtus enim cogitativa apud Aristotelem est virtus distinctiva individualeis, scilicet quod non dstinguit aliquid nisi individualiter, non universaliter. Declaratum est enim illic quo virtus cogitativa non est nisi virtus que distinguit intentionem rei sensibilis a suo idolo ymaginato. Commentarivm magnvm, 415: 59-64; traducción inglesa en Taylor, «Remarks», 223.

${ }^{184} \mathrm{Per}$ continuationem intentionis intellecte cum nobis, et sunt intentiones ymaginate, Commentarivm magnvm, 405: 518-519.

${ }^{185}$ Id., 406: 559-561.

${ }^{186}$ Id., 401: 426-427. Teofrasto y Temistio identificarían este tercer entendimiento con el entendimiento en hábito: Commentarivm magnvm, 390: 111-115; cf. Them. De anima paraphrasis, 95.

${ }^{187}$ Commentarivm magnvm, 406: 566-574. Para Temistio, cf. De anima paraphrasis, 100, y 108
} 
nas, a saber, el agente y el receptivo; la tercera, sin embargo, es generable y destructible en un aspecto y eterna en el otro ${ }^{187}$.

¿Qué es el entendimiento factum? Averroes no lo explica aquí, pero en otro lugar nos dice que no hay otros entendimientos en acto más que los especulativos, que son generables y corruptibles por causa de sus objetos y eternos por causa del entendimento material ${ }^{188}$. Así pues, el hombre es entendimiento especulativo, y mientras Temistio insistiría en que somos entendimiento agente, mejor dicho, esto es lo que entiende Averroes ${ }^{189}$, éste destaca la componente del entendimiento material. Este entendimiento es «único para todos los hombres» y contiene unos principios comunes a toda la especie humana, que es eterna. Unidad y eternidad son indisolubles.

De este modo, el discurso averroico, que quiere explicar el conocimiento intelectual, sus fundamentos y su repercusión en la naturaleza humana, fue leído como un discurso en favor de la inmortalidad colectiva, y no individual, del hombre. Una de las consecuencias fue su condena por la iglesia.

Sin embargo, la coronación de los grandes comentarios es el Tafsìr mā ba'd al-tabí'a, que comenta la Metafisica hasta el libro lambda, es decir, no comenta los libros $\mathrm{M}$ y N, y ha sido editado por M. Bouyges ${ }^{190}$ sobre la base del único manuscrito existente ${ }^{191}$. ¿Cuándo lo escribió? Es la obra de mayor envergadura de Averroes, para la que necesitó mucho tiempo y madurez. Bouyges y otros coinciden en situar la elaboración del comentario hacia el final de su vida, y recordemos que murió en 1198. En apoyo de esta tesis están unas palabras del propio Averroes, en relación con su proyecto de desarrollar una astronomía conforme a los principios aristotélicos, proyecto que anunciaba en su comentario al De caelo. En este comentario a la Metafisica, dice textualmente:

${ }^{188}$ Commentarvm magnvm, 401: 419-424.

${ }^{189}$ Sobre la interpretación "creativa» de Averroes ver Gutas, D. «Averroes on Theophrastus, through Themistius», en Averroes and the Aristotelian Tradition, 139-140, y las observaciones de M. Lyons en The Arabic Version, 176-178

${ }^{190}$ Averroes, Tafsìr mä ba'd al-tabī'a, Beirut, 1938-52, Bibliotheca arabica scholasticorum V- VII, reimp. 1973. El orden es الزاء الزاء الماء الدال البليم الباء الألف الكبرى الألف الصغرى. اللام الياء الطاء اللحاء. Falta el comienzo de Met. I, segundo en el orden de Averroes, y que corresponde al capítulo 1. Según una observación, pienso que del propio Averroes, el libro I, álpha meizon, no se encontraba en el "original árabe": Tafsìr, 54: 3-5. Cuando Averroes lo encontró, no sabía que era el primero, y su criterio hizo ponerlo segundo.

${ }^{191}$ Biblioteca de la Universidad de Leiden, cod. or. 2074. 
En mi juventud confiaba llevar a cabo esta investigación, pero en esta vejez mía he perdido la esperanza, pues las dificultades me lo han impedido ${ }^{192}$.

En contra, sin embargo, están las palabras de Averroes al final de su taljiș de la Metafisica (ver supra), anunciando su intención de comentar «palabra por palabra» la Metafisica, en primer lugar. Como solución se ofrece el fenómeno de las revisiones: Averroes escribiría el tafsir en la década de los 1180, y lo revisaría posteriormente, una o varias veces.

Existen numerosos manuscritos con la traducción hebrea, y Steinschneider señala que la mayoría de los manuscritos dan como autor a Moshe ben Shelomo, de Salon, que vivía en Beaucaire hacia 1310-1320 193. Hay dos traducciones latinas: la antigua, y completa ${ }^{194}$, de Michael Scot (m. hacia 1250), que aparece en la edición Juntina ${ }^{195}$ y otra incompleta, de Helia del Medigo (m. 1493) ${ }^{196}$, editada por I. Manardo, seguramente a partir del hebreo, lengua de la que $\mathrm{He}-$ lia tradujo muchos textos. Lo que está fuera de toda duda es que no es una traducción del comentario medio, taljīss, sino del mayor, šarh. En la edición de Manardo tenemos el comentario de Averroes al capítulo primero del Libro I, que falta en la de los Ivncta ${ }^{197}$.

Este gran comentario ha sido objeto de traducciones anotadas en tiempos recientes: Aubert Martin ${ }^{198}$ y Charles Genequand tradujeron ${ }^{199}$ y estudiaron el del libro XII. Nabil Elsakhawi se ha dedicado al

${ }^{192}$ Tafsìr mä ba'd al-tabī'a, vol. 3, p. 1664: 2-4. Para la referencia al De Caelo, ver nota 47.

${ }^{193}$ Die hebräischen Übersetzungen, 171.

${ }^{194}$ Con una excepción: la del comienzo del libro I, álpha meízon, capítulo 1, pues también falta en la versión latina.

${ }_{195}$ Octauum volumen, Aristotelis Metaphysicorvm libri XIIII cum Averrois Cordvbensis in eosdem commentariis et epitome Venecia, 1562.

${ }^{196}$ Tomus octauus operum Aristotelis... Metaphysicam... cvm Averrois Cordvbensis duplici expositione, media scilicet hactenus haudquaquam excusa usque ad septimum librum Venecia, 1560. La edición contiene la traducción de M. Scot del gran comentario, pero lo que considera media expositio, de hecho es la traducción de Helia del Medigo del comentario mayor, que llega hasta el libro VII, Metaphysica 1037 b 8 (fol. 233 E). El editor afirma que es una traducción del árabe ex Arabico in nostrum.

${ }^{197}$ Empieza: Intentio Aristotelis in hoc libro fuit scrutari de scientia diuinarum rerum, quid et qualis sit, f. $5 \mathrm{~B}$.

${ }_{198}$ Averroès, Grand Commentaire de la Métaphysique d'Aristote, livre Lām-Lambda, traduit de l'arabe et annoté. París, 1984.

${ }^{199}$ Ibn Rushd's Metaphysics. Leiden, 1984. 
del libro VII ${ }^{200}$. Laurence Bauloye incluye en su tesis doctoral la traducción del comentario al libro III ${ }^{201}$.

El comentario de Averroes a la obra se inicia sin ningún prólogo, tal como nos ha llegado; en cambio, al comienzo del comentario al libro XII, sí tenemos un proemio ${ }^{202}$ que nos ilumina sobre el proyecto de Averroes:

Ni Alejandro [de Afrodisia] ni ninguno de los comentadores posteriores a él compusieron un comentario o una exposición de los libros de esta ciencia [metafísica] más que de este libro [XII]. Hemos hallado que Alejandro tiene un comentario [tafsir] de aproximadamente dos tercios del libro, y que Temistio tiene una exposición [taljiș $]$ entera.

A mí me ha parecido que lo mejor es exponer lo que dice Alejandro en cada sección de su exposición, de la manera más clara y concisa posibles. Cuando Temistio añada algo a éste o dude de algo, lo introduciremos, de la misma manera que indicaremos lo que nosotros añadimos o dudamos ${ }^{203}$.

Averroes contrapone taljīs a tafsìr. De los libros de la Metafisica no tiene ningún comentario o paráfrasis más que del libro XII: Alejandro es autor de un tafsìr y Temistio, de un taljịs. Así Averroes puede hacer un taljīs, exponer, el tafsĩr de Alejandro, pero no del de Temistio.

Por tanto, Averroes se ayuda de Alejandro de Afrodisia ${ }^{204}$, de Temistio ${ }^{205}$, aunque a éste lo critique con frecuencia, casi tanto como a Avicena, y además conoce el comentario de Nicolás de Damasco. Nicolás sostenía que la disposición de los libros de la Metafisica no responde a ningún orden o jerarquía ${ }^{206}$, lo que Averroes y Alejandro niegan: los libros están ordenados de lo menos a lo más noble, siguen una jerarquía de valor.

En efecto, la interpretación de Alejandro que Averroes hace propia dice que el objeto del estudio aumenta en valor hasta el libro XII,

${ }^{200}$ Lille: También L. Bauloye tradujo unos capítulos en «Averroès: Grand commentaire de la Métaphysique d'Aristote, Z1 et Z2. Traduction et notes», BEO 49 (1997), 53-73, o La question de l'essence, Louvain-la Neuve, 1997, 99-120, para Met. Z1. 1999.

${ }^{201}$ Averroès et les apories de la Métaphysique d'Aristote, Universidad de Lieja,

${ }^{202}$ Tafsìr $m a \bar{a} b a^{\prime} d$ al-țabi' $a$, ed. Bouyges, vol. 3, 1393-1413. Doble versión latina en Octauum volumen, fols. 286-290, ambas a partir del hebreo.

${ }^{203}$ Tafsìr mä ba'd al-tabi' $a$, ed. Bouyges, 1393: 4-194:2.

${ }^{204}$ In Aristotelis Metaphysica commentaria. Ed. M. Hayduck,, Berlin, 1891. CiAG 1. Scholia 668-721.

${ }^{205}$ In Aristotelis Metaphysicorum Librum $\Lambda$ paraphrasis, Hebraice et latine. Berlin, 1903 CiAG 5.5.

${ }^{206}$ Tafsìr mä ba'd al-tabí' $a$, ed. Bouyges, 1405: 6-7. 
y que lo que sigue a éste, es decir, los libros XIII y XIV, solamente tratan de las aporías de esta disciplina. Los primeros libros de la $\mathrm{Me}$ tafisica tendrían, según esta interpretación, un valor propedéutico. La Metafisica, por tanto, consta de tres partes: una preparatoria, otra dedicada a su contenido propiamente dicho, y otra, la de los libros Mim y Nün, refutando las ideas de Platón y de los pitagóricos. El comentario mayor, como acabamos de decir, no llega a estos dos libros.

El libro pequeño Âlif (II, pero I en la tradición árabe) presenta el tema. Álif grande (I, pero II en árabe) nos ilustra sobre las causas universales de todos los entes. El libro $B \bar{a}^{\prime}$ (III) expone las dificultades que afectan al estudio de la metafísica. También $\hat{Y} \bar{m} m$ (IV), aunque nos pueda sorprender la afirmación de Averroes, es un libro propedéutico, pues contiene la «lógica particular» de esta ciencia y trata del principio de no-contradicción ${ }^{207}$. Además, Averroes lo relaciona con las aporías de III, $B \tilde{a}^{\prime}$, que aquí encuentran solución... En cuanto al léxico que es el libro V, $D \bar{a} l$, está clara su función preparatoria a la ciencia primera.

Aristóteles no entraría en esta ciencia más que a partir del libro VI, $H \bar{a}$ '. Como en $B \bar{a}$ ' se habla de la necesidad de una ciencia que estudie el ente en cuanto ente ${ }^{208}$, en ese libro VI, Aristóteles examinaría las causas de las tres clases de entes (entidades, huwiy āt): el ente que existe por accidente, el ente que existe dentro del alma y el que existe fuera del alma ${ }^{209}$. Un eslabón más elevado corresponde al estudio del ente que existe «de verdad», aquel que existe fuera del alma, y ante todo de su causa, que es la sustancia (yawhar) ${ }^{210}$. Así pues, los libros $W \bar{a} w$ (VII) y $Z \bar{a} y$ (VIII) tratan de «los principios de la sustancia sensible» ${ }^{211}$. Los libros $H \bar{a}^{\prime}$ (IX) y $T \bar{a}^{\prime}$ (X) quedan para examinar «las propiedades generales del ente como ente» ${ }^{212}$, y el $Y \bar{a}$ ' (XI), para analizar el movimiento y el infinito desde un punto de vista distinto al que se utilizó en la Física ${ }^{213}$.

${ }^{207}$ Tafsìr mā ba'd al-tabí'a, ed. Bouyges, 1400: 4-8.

${ }^{208}$ Id., ed. Bouyges, 1401: 11-13; cfr. Metaphysica 1003 a 21-22.

${ }^{209}$ Id., ed. Bouyges, 1401: 2-5; cfr. Metaphysica 1025 b 3-4.

${ }^{210} \mathrm{Id}$., ed. Bouyges, 1402: 5-6.

${ }^{211}$ Id., 1403: 10-14.

${ }^{212} I d$., 1403: 11-18.

${ }^{213}$ Averroes habla del libro XI como $y \bar{a}$ ', y echa de menos el libro $K a \bar{f}$, pues no se da cuenta de que kappa es el libro XI. Ver la observación de Aubert Martin en Averroès, Grand Commentaire, 41, nota 65. 
El eslabón más alto de todos se encuentra en el libro Lām (XII): en conocer todas las clases de sustancia, y en demostrar que el principio de la sustancia primera es sustancia en sí. Esta Sustancia Primera es la razón de los principios del universo ${ }^{214}$.

Averroes y Alejandro, el musulmán y el politeísta, coinciden en su interpretación. Lo divino es la sustancia por excelencia.

A través del estudio precedente creo haber aportado suficientes pruebas para formular a las conclusiones siguientes:

Taljịs y tafsìr (a veces utiliza šarh) son los dos géneros escogidos por Averroes para llegar a una comprensión fundamental de Aristóteles; otras formas son secundarias. Para uno y otro género, Averroes se inspira fundamentalmente en los comentadores helenísticos: Alejandro y Temistio. Referencias a los comentarios coránicos, como modelo, no las he encontrado. El género de los comentarios de Avempace (šarh) puede influir en los mal llamados «comentarios menores», pero no aquí. En cambio, Alfarabi es autor de comentarios formalmente parecidos a los tafäsīr de Averroes.

La intención del taljị̣ es una exposición sistemática del pensamiento de Aristóteles, siguiendo el esquema arbóreo ( $\hat{y} u z$ ', fașl, qism o maqāla, ŷumla, fașl), de lo que se conoce por divisio textus, pero que sólo en contados casos fue capaz de llevarla a cabo. En otros selecciona pasajes del texto aristotélico, o los parafrasea, para comentarlos acto seguido.

La intención del tafsir es un comentario literal y una interpretación pasaje por pasaje, en el marco de la cual procura exponer sistemáticamente el pensamiento del maestro. Abundan, sin embargo, excursos muy fructíferos.

Taljị y tafsir corresponden fundamentalmente a dos fases, la de los talājị̦ precede a la de los tafāsìr, y ocuparía el período 1168-1175, mientras la segunda se situaría en la década de 1180, pero no deben excluirse revisiones.

Podemos pensar que los destinatarios del taljị y del tafsir eran distintos: el grupo al que iban destinados los grandes comentarios sería más reducido; poco más podemos afirmar y sería aventurado construir hipótesis sobre esto.

${ }^{214}$ Tafsìr mā ba'd al-țabī'a, ed. Bouyges, 1405: 1. 
La unidad del pensamiento averroico es omnipresente en unos y otros comentarios. La unidad en el sistema que Aristóteles no llegó a establecer la explica y la interpreta Averroes.

\section{RESUMEN}

Averroes fue fílósofo, médico y jurista, pero en el mundo latino se le conoció ante todo como Commentator, el comentador de Aristóteles. Pertenecen a esta actividad dos tipos de escritos: la exposición sistemática, taljị̦, y la exégesis literal, tafsir, los cuales son objeto de análisis aquí. Son las dos fases de un proyecto que le ocupa muchos años, y que busca comprender íntegramente a Aristóteles como personificación de la sabiduría.

\section{SUMMARY}

Averroes was a philosopher, a physician and a jurist, although he was known in the Latin world as the Commentator, i.e., the commentator of Aristotle. Two kinds of writings reflect this activity: systematic expositions of Aristotle's works, talkhis, and literal exegeses of many of them, tafsir, both being the subject of research here. They build the two stages of a project lasting for many years and aiming at the full understanding of Aristotle as the very wisdom. 